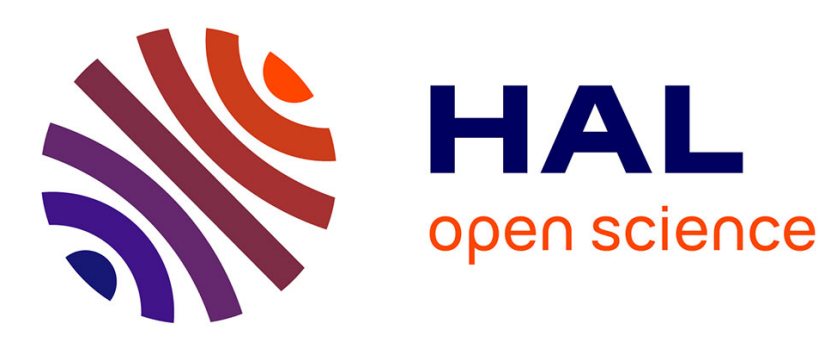

\title{
Degradation of cellulose at the wet-dry interface. II. Study of oxidation reactions and effect of antioxidants
}

Myung-Joon Jeong, Anne-Laurence Dupont, E René de La Rie

\section{To cite this version:}

Myung-Joon Jeong, Anne-Laurence Dupont, E René de La Rie. Degradation of cellulose at the wetdry interface. II. Study of oxidation reactions and effect of antioxidants. Carbohydrate Polymers, 2014, 101, pp.671 - 683. 10.1016/j.carbpol.2013.09.080 . hal-01491055

\section{HAL Id: hal-01491055 \\ https://hal.science/hal-01491055}

Submitted on 16 Mar 2017

HAL is a multi-disciplinary open access archive for the deposit and dissemination of scientific research documents, whether they are published or not. The documents may come from teaching and research institutions in France or abroad, or from public or private research centers.
L'archive ouverte pluridisciplinaire HAL, est destinée au dépôt et à la diffusion de documents scientifiques de niveau recherche, publiés ou non, émanant des établissements d'enseignement et de recherche français ou étrangers, des laboratoires publics ou privés. 


\title{
Degradation of cellulose at the wet-dry interface. II. Study of oxidation reactions and effect of antioxidants
}

\author{
Myung-Joon Jeong ${ }^{\mathrm{a}, 1}$, Anne-Laurence Dupont ${ }^{\mathrm{a}, *}$, E. René de la Rie ${ }^{\mathrm{b}, 2}$ \\ a Centre de Recherche sur la Conservation des Collections, Muséum National d'Histoire Naturelle, CNRS-USR 3224, 36 rue Geoffroy-Saint-Hilaire, 75005 \\ Paris, France \\ ${ }^{\mathrm{b}}$ National Gallery of Art, DCL-Scientific Research Department, 401 Constitution Avenue NW, Washington, DC 20565, USA
}

\section{A R T I C L E I N F O}

\section{Article history:}

Received 31 May 2013

Received in revised form 26 August 2013

Accepted 19 September 2013

Available online $\mathrm{xxx}$

\section{Keywords:}

Cellulose

Hydroxyl radical

Hydroperoxide

Molar mass

Antioxidant

Hygrothermal aging

\begin{abstract}
A B S T R A C T
To better understand the degradation of cellulose upon the formation of a tideline at the wet-dry interface when paper is suspended in water, the production of chemical species involved in oxidation reactions was studied. The quantitation of hydroperoxides and hydroxyl radicals was carried out in reverse phase chromatography using triphenylphosphine and terephthalic acid, respectively, as chemical probes. Both reactive oxygen species were found in the tideline immediately after its formation, in the range of micromoles and nanomoles per gram of paper, respectively. The results indicate that hydroxyl radicals form for the most part in paper before the tideline experiment, whereas hydroperoxides appear to be produced primarily during tideline formation. Iron sulfate impregnation of the paper raised the production of hydroperoxides. After hygrothermal aging in sealed vials the hydroxyl radical content in paper increased significantly. When aged together in the same vial, tideline samples strongly influenced the degradation of samples from other areas of the paper (multi-sample aging).

Different types of antioxidants were added to the paper before the tideline experiment to investigate their effect on the oxidation reactions taking place. In samples treated with iron sulfate or artificially aged, the addition of Irgafos 168 (tris(2,4-ditert-butylphenyl) phosphate) and Tinuvin 292 (bis(1,2,2,6,6pentamethyl-4-piperidyl) sebacate and methyl 1,2,2,6,6-pentamethyl-4-piperidyl sebacate) reduced the concentration of hydroperoxides and hydroxyl radicals, respectively. Tinuvin 292 was also found to considerably lower the rate of cellulose chain scission reactions during hygrothermal aging of the paper.
\end{abstract}

(C) 2013 Elsevier Ltd. All rights reserved.

\section{Introduction}

Tidelines (brown lines) in paper can affect degradation of cellulose in the brown area itself and in neighboring areas (Jeong, Dupont, \& De la Rie, 2012; Souguir, Dupont, \& De la Rie, 2008). They can form in historical papers and books at the wet-dry interface upon local exposure to water or high relative humidity (Bone \& Turner, 1950; Dupont, 1996a; Eusman, 1995; Hofenk de Graaff, 1994; Madaras \& Turner, 1953). Understanding the degradation of cellulose due to a tideline is therefore important for paper conservation purposes. Various degradation products evidencing

\footnotetext{
* Corresponding author. Tel.: +33 140795307; fax: +33 140795312

E-mail addresses: myung-joon.jeong@boku.ac.at (M.-J. Jeong), aldupont@mnhn.fr (A.-L. Dupont), e.r.delarie@uva.nl (E.R. de la Rie).

1 Present address: University of Natural Resources and Applied Life Sciences, Department of Chemistry, Muthgasse 18, 1190 Vienna, Austria.

2 Present address: University of Amsterdam, Hobbemastraat 22, 1071 ZC Amsterdam, The Netherlands.
}

oxidation have been identified in tidelines (Bogaty, Campbell, \& Appel, 1952; Dupont, 1996b; Jeong et al., 2012; Souguir et al., 2008). Among those, low molar mass organic acids, can directly affect cellulose via acid catalyzed hydrolysis, which results in a decrease in the molar mass (Fengel \& Wegener, 1984; Souguir et al., 2008). Hydroperoxides have also been found in tidelines in larger quantities than in other areas of the paper (Souguir et al., 2008).

Cellulose oxidation may involve the often cited oxidation of the C2 and C3 hydroxyl groups to ketone groups and of the C6 hydroxyl group to a carboxylic acid group (Lai, 2001). Much more destructive oxidation involves free radical reactions. Free radical oxidation in organic materials encompass a complex series of reactions and has been studied widely, although perhaps less so in cellulose. Some of the free radical reactions possible in cellulose are presented in Scheme 1 (Luo, Abbas, Zhua, Deng, \& Tang, 2008; Prousek, 2007; Scott, 1993). They involve hydrogen abstraction from a cellulose molecule and formation of an alkyl radical. Certain hydrogen atoms are more easily abstracted than others, such as those in an $\alpha$-position to a double bond and those attached to a tertiary carbon atom. In Scheme 1 examples are indicated of $\mathrm{H}$-abstraction on C3, 


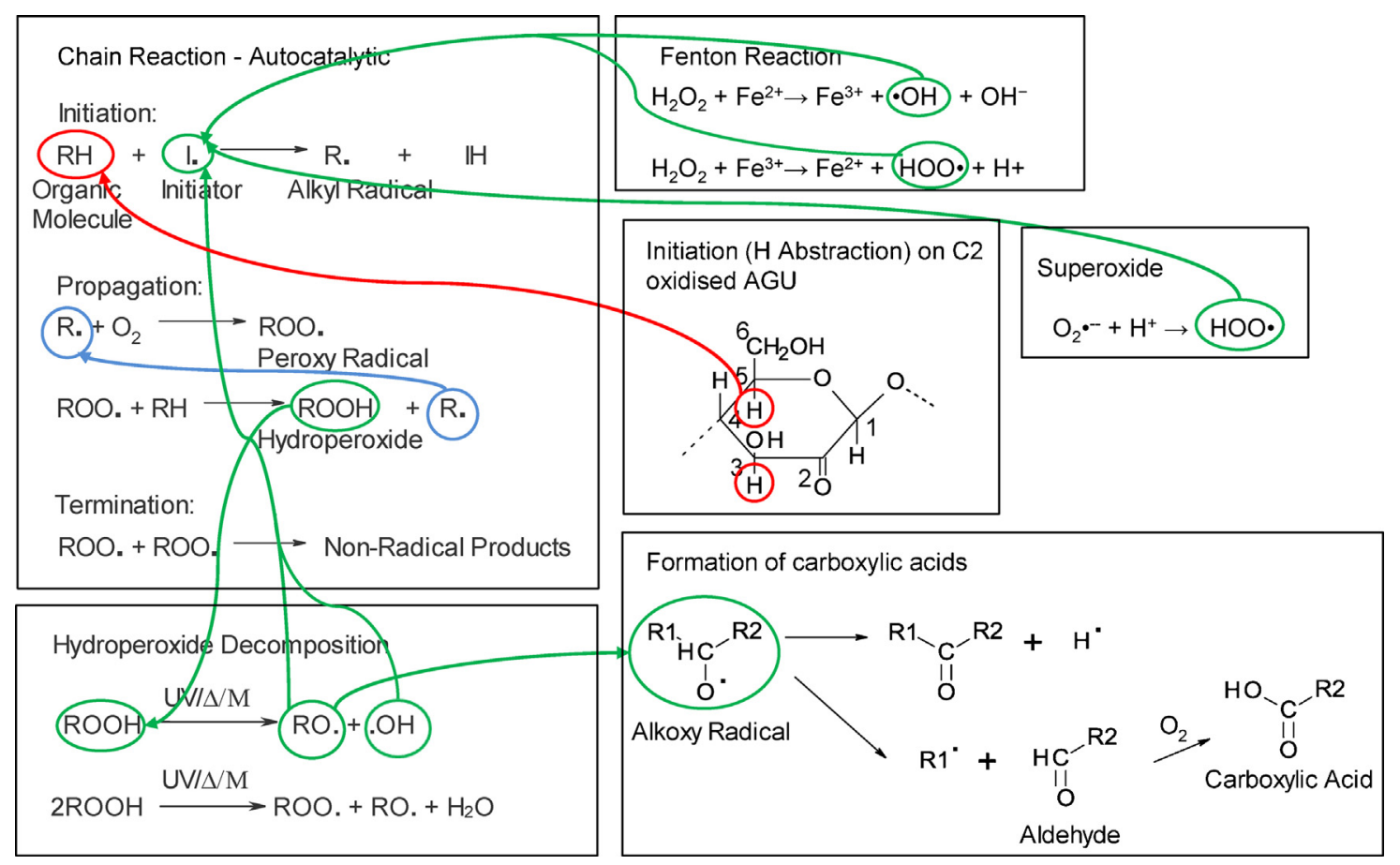

Scheme 1. Autoxidation chain reaction and related free radical reactions. UV = UV catalyzed reaction, $\Delta=$ thermal reaction, $M=$ metal ion catalyzed reaction.

which is in an $\alpha$-position to a double bond formed after oxidation of the $-\mathrm{OH}$ on $\mathrm{C} 2$ to a ketone group, and on the tertiary carbon atom $\mathrm{C5}$. The alkyl radical rapidly reacts with oxygen to form a peroxy radical. The peroxy radical abstracts a hydrogen from another molecule and forms a hydroperoxide (R-OOH). Hydroperoxides, the initial products of oxidation, easily decompose to yield peroxy, alkoxy and hydroxyl radicals, which further participate in the free radical chain process, which is therefore also considered autocatalytic (Scott, 1993). Many more complex reactions may take place. In an aqueous environment, Fenton reactions, in which hydrogen peroxide is decomposed in the presence of $\mathrm{Fe}^{2+} / \mathrm{Fe}^{3+}$, as well as other transition metal ions such as $\mathrm{Cu}^{2+} / \mathrm{Cu}^{1+}$, to yield free radicals, can furthermore play a role (Kolar, 1997; Kolar, Strlič, Novak, \& Pihlar, 1998; Walling, 1975). Superoxide radical anion is believed to play a part in aqueous oxidation reactions (Kočar et al., 2005). It is known to be involved in a stepwise one-electron reduction of molecular oxygen leading to the production of hydrogen peroxide (Prousek, 2007).

Antioxidants interfere with free radical oxidation by eliminating reactive species. They can be divided into free radical scavengers, also known as chain-breaking antioxidants, which remove free radicals (Pospíšil \& Nespurek, 1995; Scott, 1993), primarily peroxy radicals, and preventive antioxidants, which convert hydroperoxides to their corresponding alcohols (Scott, 1993). Hydroperoxide decomposers are often used in combination with free radical scavengers as they work synergistically.

Antioxidants have been rarely employed in paper. For the most part they have been utilized in attempts to stabilize iron gall ink containing papers, in which oxidation reactions catalyzed by iron ions are believed to play a role. Potassium iodide and other halides (Malešič, Strlič, Kolar, \& Polanc, 2005), as well as calcium and magnesium phytate have been studied for this purpose (Kolar et al., 2007; Neevel, 1995). Although the latter have been described as preventive antioxidants in the literature, it appears that their main function is as chelating agents for iron ions to suppress the Fenton reaction. The chelating effects of EDTA, citrate and other compounds have also been studied (Strlič, Kolar, \& Pihlar, 2001). Although present at low concentrations, iron and other metal ions may be a factor in the tideline phenomena observed on pure cellulose paper.

Lignin, a common constituent in paper, has been reported to function as an antioxidant although it may also cause discoloration (Schmidt, Rye, \& Gurna, 1995). It is structurally similar to phenolic antioxidants. Hindered phenols are powerful chain breaking antioxidants (Pospíšil \& Nespurek, 1995). They have the drawback of developing colored transformation products and are therefore not suitable for use in paper. Hindered amine stabilizers (HAS) are powerful free radical scavengers that do not form colored transformation products (Gugumus, 1994). They are oxidized by peroxy radicals to nitroxyl radicals, which are considerably more stable and can be regenerated via a process that involves alkyl radicals and peroxy radicals (Scheme 2). The chemistry of HAS is complex and cannot be done justice in the context of this paper. In this study the effects of the HAS Tinuvin 292 (bis(1,2,2,6,6-pentamethyl-4piperidyl) sebacate and methyl 1,2,2,6,6-pentamethyl-4-piperidyl sebacate) were investigated. Preventive antioxidants such as tetrabutylammonium bromide, 1-ethyl-3-methylimidazolium bromide and Irgafos 168 (tris(2,4-ditert-butylphenyl)phosphite), a phosphite with presumably better hydrolytic stability than most phosphites (Tocháček \& Sedlár., 1993), were also included in this study (Scheme 2). The molecular structures of the antioxidants can be found in Table 1 .

The aim of this research was to further study oxidation reactions occurring during tideline experiments. Only the effects of water migration were investigated but it is plausible that exposure to high or fluctuating humidity affects similar reactions. The formation of hydroperoxides and hydroxyl radicals in papers with or without treatment with antioxidants was studied to better understand the oxidation process occurring in the tideline and neighboring areas in the paper. To assess the role of metal ions, Whatman paper was doped with various concentrations of ferrous sulfate (Calvini \& Silveira, 2008). Some papers were artificially aged in order to enhance degradation and predict future behavior.

Among the various methods available for quantifying hydroperoxides and hydroxyl radicals, chromatographic methods using triphenylphosphine and terephthalic acid as probes, respectively, 
(a) Free radical scavengers

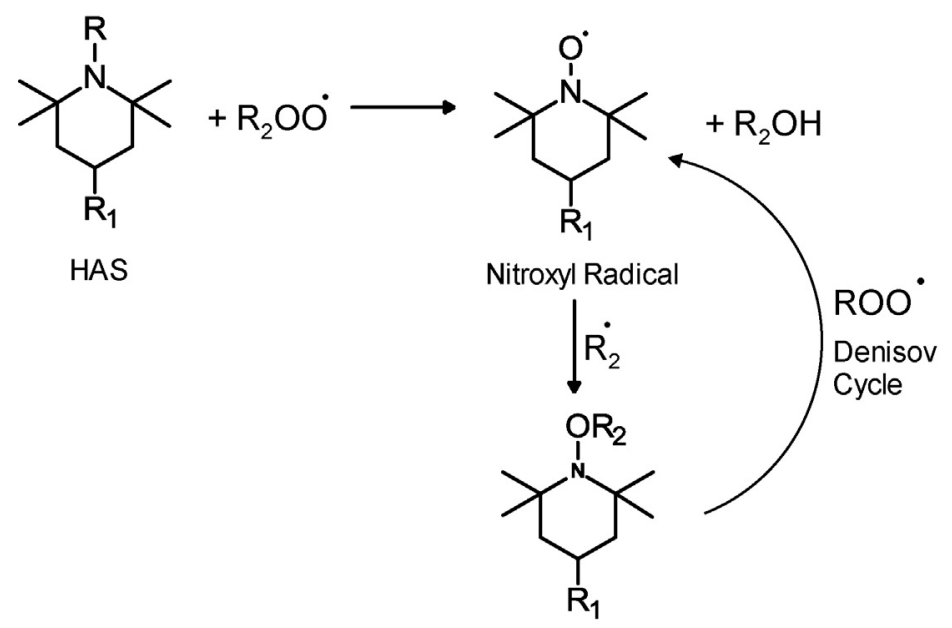

Hydroxylamine Ether

(b) Preventive Antioxidant
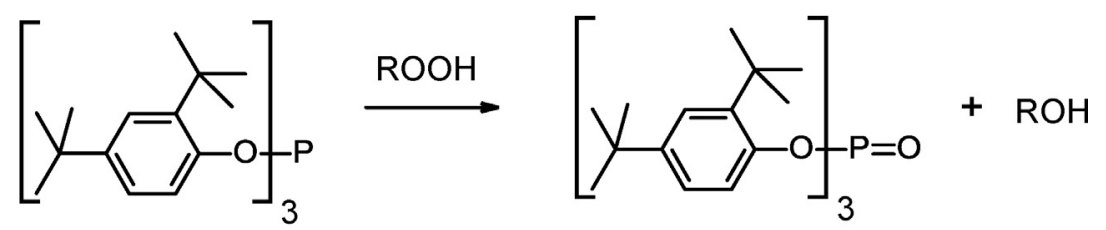

Irgafos 168

Scheme 2. Reaction pathway of antioxidants: free radical scavengers (a) and preventive antioxidants (b).

Table 1

Antioxidants (AO) used and their concentration in Whatman No. 1 paper.

\begin{tabular}{|c|c|c|c|}
\hline $\begin{array}{l}\text { Antioxidants (molar } \\
\text { mass) }\end{array}$ & Molecular formulae & $\begin{array}{l}\text { Concentrations (\% } \\
\text { wt/v)/solvent }\end{array}$ & $\begin{array}{l}\text { Total AO in paper }(\% \mathrm{wt} / \mathrm{wt}) \\
{\left[\mu \mathrm{mol} \mathrm{g}^{-1}\right]}\end{array}$ \\
\hline $\begin{array}{l}\mathrm{I} 168 \\
\left(646.9 \mathrm{~g} \mathrm{~mol}^{-1}\right)\end{array}$ & & $\begin{array}{l}0.2 \text { /acetone } \\
0.8 \text { /acetone }\end{array}$ & $\begin{array}{l}0.5[0.77] \\
2.0[3.09]\end{array}$ \\
\hline $\begin{array}{l}\mathrm{T} 292 \\
\left(481.2 \mathrm{~g} \mathrm{~mol}^{-1}\right) \\
(0.8 \times 509)+(0.2 \times 370)\end{array}$ & 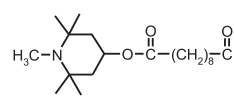 & $\begin{array}{l}0.2 \text { /acetone } \\
0.8 \text { /acetone }\end{array}$ & $\begin{array}{l}0.5[1.04] \\
2.0[4.16]\end{array}$ \\
\hline I168:T292 (1:1) & See structures above & $\begin{array}{l}\text { 0.1:0.1/acetone } \\
\text { 0.4:0.4/acetone }\end{array}$ & $\begin{array}{l}0.5[0.39: 0.52] \\
2.0[1.55: 2.08]\end{array}$ \\
\hline $\begin{array}{l}\mathrm{tBABr} \\
\left(322.4 \mathrm{~g} \mathrm{~mol}^{-1}\right)\end{array}$ & & 0.68/methanol & $1.7[5.27]$ \\
\hline tBABr:T292 (0.85:1) & See structures above & $\begin{array}{l}0.34 / \text { methanol } \\
0.4 / \text { acetone }\end{array}$ & $\begin{array}{l}1.85 \\
{[2.64: 2.08]}\end{array}$ \\
\hline $\begin{array}{l}\text { EMIMBr } \\
\left(191.1 \mathrm{~g} \mathrm{~mol}^{-1}\right)\end{array}$ & & 0.4/acetone & $1.0[5.23]$ \\
\hline EMIMBr:T292 (0.5:1) & See structures above & 0.2:0.4/acetone & $1.5[2.62: 2.08]$ \\
\hline
\end{tabular}


were chosen (Linxiang et al., 2004; Nakamura \& Maeda, 1991; Souguir et al., 2008; Yan et al., 2005). Molar mass of cellulose was also evaluated chromatographically (Dupont, 2003).

\section{Experimental}

\subsection{Materials and chemicals}

Whatman No. 1 paper sheets $(15$ (or 7.5$) \mathrm{cm} \times 28 \mathrm{~cm}$ ) composed of circa $100 \%$ cotton cellulose fibers (alpha cellulose content $\geq 98 \%$ ) were used to produce the brown lines.

Triphenylphosphine (TPP) (ReagentPlus ${ }^{\circledR} 99 \%$ ), and terephtalic acid (TPA) (98\%) were purchased from Sigma-Aldrich. Triphenylphosphine oxide (TPPO) (98\%), N,N-dimethylacetamide and lithium chloride were from Fluka. Potassium dihydrogen phosphate (99.5\%), phosphoric acid (>98\%) and methanol (>99.9\%) were obtained from Acros. Hydroxyterephthalic acid (HTPA) was synthesized in the laboratory according to the protocol by Yan et al. (2005).

Four different antioxidants were used. Tinuvin 292 (T292) (bis(1,2,2,6,6-pentamethyl-4-piperidyl) sebacate and methyl 1,2,2,6,6-pentamethyl-4-piperidyl sebacate) and Irgafos 168 (I168) (tris(2,4-di-tert-butylphenyl)phosphate) were provided by Ciba (now BASF). Tetrabutylammonium bromide (TBABr) (98\%) and 1-ethyl-3-methylimidazolium bromide (EMIMBr) (>97\%) were purchased from Sigma-Aldrich.

\subsection{Production of tidelines}

Several sheets of paper were suspended vertically, 4-cm apart, the lower end immersed $2.5 \mathrm{~cm}$ deep in deionized water ( $1 \mathrm{~L}$ ) (Milli $\mathrm{Q}$, Millipore) at $23^{\circ} \mathrm{C}$ in the dark. The wet/dry interface stabilized after about $2 \mathrm{~h}$ at approximately $17-18 \mathrm{~cm}$ from the water surface. The experiment usually lasted $16 \mathrm{~h}$ unless otherwise stated. After formation of the tideline, papers were dried in ambient air and equilibrated for at least $24 \mathrm{~h}$ at stable ambient conditions $\left(23^{\circ} \mathrm{C}\right.$ and $45 \pm 3 \%$ relative humidity $(\mathrm{RH})$ ). Several areas in the paper were analyzed: the area above the tideline (aTL), the tideline area (TL), and the area below the tideline (bTL). The latter was sub-divided into an upper area bTL (U-bTL), a middle area bTL (M-bTL), and a lower area bTL, near the water surface level (L-bTL). In some cases the 'light brown' area adjacent to the tideline (LB-TL), due to diffusion of the migrating species, and the bottom area below water level (B-bTL) were also measured (Fig. 1). For analysis, the tideline was cut from the paper as a thin ribbon, as close on each side of the brown boundaries as possible.

\subsection{Analysis of hydroperoxides by RP-HPLC}

\subsubsection{Sample preparation}

To enable a significant production of hydroperoxides and a measurable effect of the antioxidants, some papers were pretreated with iron sulfate. Three sheets were immersed in $420 \mathrm{~mL}$ $\mathrm{FeSO}_{4} \cdot 7 \mathrm{H}_{2} \mathrm{O} 0.05 \%(\mathrm{wt} / \mathrm{v})(1.80 \mathrm{mM})$ for $10 \mathrm{~min}$, after which water was squeezed out by pressing gently with blotting paper and the paper was left to dry at stable ambient T/RH conditions for $4 \mathrm{~h}$ before the impregnation with antioxidants. The iron concentration in the samples was not measured but was expected to be about $100 \mu \mathrm{g} \mathrm{g}^{-1}$ according to literature data (Rouchon, Duranton, Burgaud, Pellizzi, \& Lavédrine, 2011), which falls in the range of iron content measured in a set of historic papers dating from the 15 th to the 18 th century ( $\sim 280 \mathrm{ppm}$ on average) (Stephens et al., 2008).

After this pretreatment, papers were impregnated with antioxidants by spreading evenly $9 \mathrm{~mL}$ of antioxidant dissolved in the appropriate solvent in known concentration, directly on their surface (Table 1). The samples were dried and equilibrated for one week at stable ambient $\mathrm{T} / \mathrm{RH}$ conditions.

The tideline experiment was carried out according to the experimental setup described in Fig. 1. After drying, the different areas were cut out. The samples TL $(5-10 \mathrm{mg}), \mathrm{LB}-\mathrm{TL}$, aTL and UbTL $(20 \mathrm{mg})$ were immersed in $1.2 \mathrm{~mL}$ TPP $(150 \mu \mathrm{M})$ prepared in water:methanol (1:3), and stirred at room temperature for $2 \mathrm{~h}$ to allow the reaction between hydroperoxides and TPP to occur. The solution was filtered using $0.2 \mu \mathrm{m}$ pores PTFE membrane filter and was analyzed immediately and after one week (standing time).

\subsubsection{Analysis}

An Agilent 1100 series HPLC system equipped with a vacuum degasser, a binary pump, an autosampler, a photodiode array detector (PDA) and a variable wavelength detector (VWD) was used. The method was adapted from a previously published procedure with some modifications (Souguir et al., 2008). The separation was carried out on a Pursuit C18 column $(2.0 \mathrm{~mm} \times 100 \mathrm{~mm}), 3-\mu \mathrm{m}$ particle-diameter (Varian) preceded by a guard cartridge (SecurityGuard, Phenomenex). The column compartment was thermostated at $25^{\circ} \mathrm{C}$. The mobile phase was a mixture of water (solvent A) and methanol (solvent $B$ ) and was used under the following linear gradient mode: $0 \mathrm{~min}, 80 \% \mathrm{~A}$ and $20 \% \mathrm{~B}, 0-5 \mathrm{~min}, 20-100 \%$ linear $\mathrm{B}, 5-12 \mathrm{~min}, 100 \% \mathrm{~B}$. The analyses lasted $20 \mathrm{~min}$ and the system was re-equilibrated up to $80 \% \mathrm{~A}$ and $20 \% \mathrm{~B}$ during 10 min before each new analysis. The flow rate was $0.3 \mathrm{~mL} \mathrm{~min}^{-1}$ and sample injection volume was $5 \mu \mathrm{L}$. The full PDA scan was made over the range $190-390 \mathrm{~nm}$. The detection wavelengths used for TPPO and TPP were 224 and $262 \mathrm{~nm}$, respectively, with the reference set at $380 \mathrm{~nm}$. The system operation, data acquisition, calibration and quantitation were performed using ChemStation for LC 3D systems (Agilent).

The sensitivity of the method was evaluated with the limit of detection (LOD) calculated as three times the signal to-noise ratio $\left(S^{\prime} \mid N\right)$, and with the limit of quantitation (LOQ) calculated as $3.33 \times$ LOD (Snyder, Kirkland, \& Glajch, 1997) when possible. The linearity of the response was established by building calibration curves with five concentration levels using individual solutions. Each calibration point was the average of two injections. The calibration curves for TPPO and TPP were done over the concentration range $5.35 \times 10^{-6} \mathrm{M}$ to $1.07 \times 10^{-4} \mathrm{M}$ and $1.93 \times 10^{-5} \mathrm{M}$ to $9.32 \times 10^{-5} \mathrm{M}$, respectively. In order to compare the results, data is reported in terms of moles of TPP or TPPO in a gram of paper.

\subsection{Analysis of hydroxyl radicals by RP-HPLC}

\subsubsection{Sample preparation}

Samples were prepared by pre-impregnating the paper with TPA before the formation of the tideline. Each paper was immersed for $3 \mathrm{~min}$ in $200 \mathrm{~mL}$ of an aqueous solution of $1 \mathrm{mM}$ TPA, which resulted in an uptake of $2.24 \mu \mathrm{mol} \mathrm{g}^{-1}$ of paper. The samples were dried and equilibrated for $20 \mathrm{~h}$ at ambient laboratory condition and the tideline experiment was performed. The optimization of the sample preparation is described in Section 2.4.2.

The antioxidant-impregnated samples were prepared by adding $0.05 \%, 0.1 \%, 0.5 \%$ and $1.0 \%(\mathrm{wt} / \mathrm{wt}$ ) of T292, I168, and mixtures T292:I168 (1:1 and 4:1). T292 and TPA were dissolved in methanol while I168 was dissolved in acetone due to poor solubility in methanol. To minimize the interference of oxidation by simple exposure to ambient air, all the samples containing TPA were equilibrated for $2 \mathrm{~h}$ only.

The extraction was done in $1.4 \mathrm{~mL}$ of water-methanol (7:3) in which about $10 \mathrm{mg}$ of each sample was immersed for $24 \mathrm{~h}$ under 
Before migration

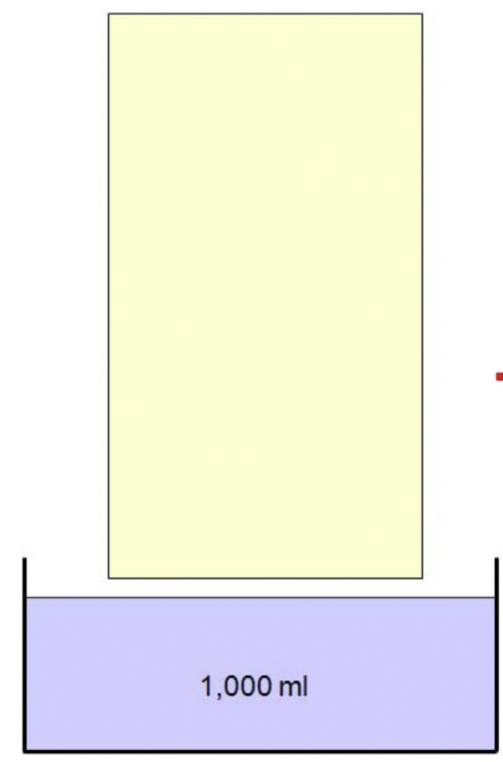

After migration $(16 \mathrm{hr})$

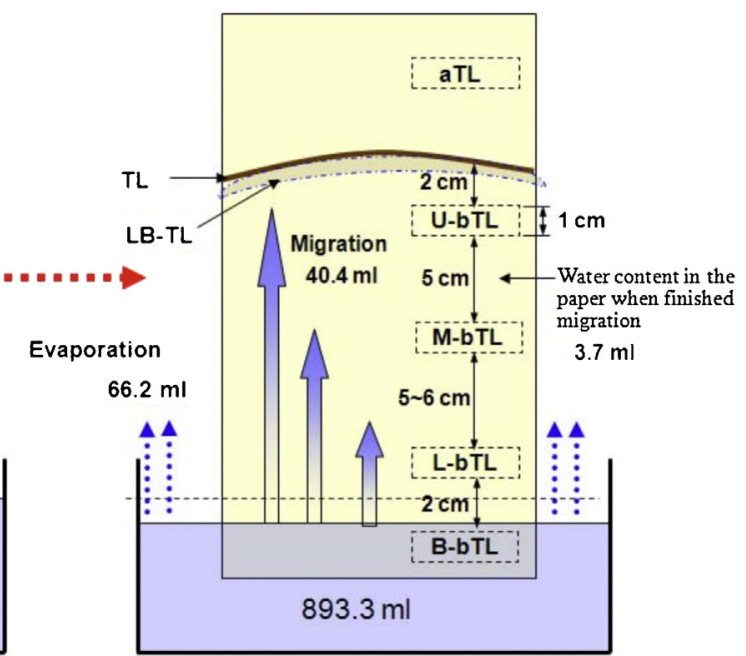

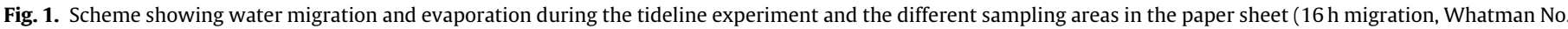
$1,28 \mathrm{~cm} \times 15 \mathrm{~cm})$.

constant stirring at room temperature. The solution was then filtered using $0.2 \mu \mathrm{m}$ pores PTFE filter.

\subsubsection{Optimization of the sample preparation}

2.4.2.1. TPA uptake in the paper. Unlike the methodology for R$\mathrm{OOH}$, using TPP, which had been developed in a previous work by the authors, several experimental parameters had to be optimized before the TPA/HTPA method could be applied, especially in the preparation of the paper samples. One of them was the extent and reproducibility of the TPA uptake in the paper. Figure SI-1(a) in the Supporting information file shows that this uptake varied in direct proportion to the TPA solution concentration. The experiment carried out on 8 paper samples immersed in $1 \mathrm{mM}$ TPA showed that the uptake was reproducible, at $2.24 \mu \mathrm{mol} \mathrm{g}^{-1}$ (RSD 2.6\%).

Increasing the immersion time in the $1 \mathrm{mMTPA}$ solution showed that the uptake was stable $\left(2.24 \mu \mathrm{mol} \mathrm{g}^{-1}\right.$ for $3 \mathrm{~min}, 2.27 \mu \mathrm{mol} \mathrm{g}^{-1}$ for $1 \mathrm{~h}, 2.36 \mu \mathrm{molg}^{-1}$ for $4 \mathrm{~h}$ ) indicating that $3 \mathrm{~min}$ is enough to achieve reproducible uptakes. This is due to a good accessibility of the solvent (methanol) in the fibrillar mesostructure of cellulose.

2.4.2.2. HTPA content with equilibration period. The HTPA content of the paper pre-impregnated with the aqueous solution of TPA $1 \mathrm{mM}$ and kept in stable ambient T/RH conditions (henceforth called equilibration) increased in a linear fashion until about $200 \mathrm{~h}$, after which it stabilized (Fig. SI-1(b) in the Supporting information file). The initial rate of production of $\mathrm{OH}^{\circ}$ in paper can be determined from the slope of the plot on the portion $0-200 \mathrm{~h}$ as $0.026 \mathrm{nmol} \mathrm{g}^{-1} \mathrm{~h}^{-1}$.

Figure SI-2 in the Supporting information file shows the HTPA content as a function of the TPA uptake in the paper after $60 \mathrm{~h}$ equilibration, this period being the total exposure time of the paper to air $(20 \mathrm{~h}$ initial $\mathrm{T} / \mathrm{RH}$ equilibration, $16 \mathrm{~h}$ water migration for the tideline experiment and $24 \mathrm{hT} / \mathrm{RH}$ post-equilibration). The HTPA content in the paper gradually increased from 0.12 to $0.64 \mathrm{nmol} \mathrm{g}^{-1}$ for TPA concentrations from 0.27 to $2.24 \mu \mathrm{mol} \mathrm{g}^{-1}$, and then essentially stabilized. From these results it appears that using a $1 \mathrm{mM}$ TPA solution for paper impregnation is sufficient for the purpose of hydroxyl radical analysis.
Table 2

Samples proportion (\%) and amount (mg) in each aging vial. Samples were preimpregnated with TPA, resulting in a concentration of TPA in the paper of $2 \mu \mathrm{mol} \mathrm{g}^{-1}$.

\begin{tabular}{llll}
\hline Aging type & aTL & TL & bTL \\
\hline aTL and bTL (without TL) (A) & $50 \%-41.4$ & & $50 \%-41.4$ \\
aTL, U-bTL and TL (B) & $50 \%-41.4$ & $25 \%-20.7$ & $25 \%-20.7$ \\
aTL, U-bTL and TL (TL in glass tube) (C) & $50 \%-41.4$ & $25 \%-20.7$ & $25 \%-20.7$ \\
\hline
\end{tabular}

\subsubsection{Hygrothermal aging of TPA impregnated samples}

Artificial aging using a scaled down procedure ASTM D6819$02 \mathrm{e} 02$ standard was carried out at $100^{\circ} \mathrm{C}$ for 2 and 5 days with $3 \mathrm{~mL}$ crimp cap vials and PTFE/butyl septa (Fig. 2 left (A-C)). The total mass of paper placed in the aging vial was downsized in order to follow the ratio of sample weight to vial volume as in the ASTM standard. All other parameters were as in the standard method. One or several areas of the paper (aTL, TL, U-bTL, M-bTL, L-bTL, BbTL) were placed in the vials in various proportions, as described in Table 2. The samples extracts were prepared as described in Section 2.4.1.

\subsubsection{Analysis}

An Agilent 1200 series HPLC system equipped with a vacuum degasser, a quaternary pump, an autosampler, a fluorescence detector (FLD) (Agilent 1100 series) and a PDA detector (Agilent 1100 series) were used. The separation was carried out on a Pursuit C18 column $(4.0 \mathrm{~mm} \times 100 \mathrm{~mm}), 5-\mu \mathrm{m}$ particle-diameter (Varian) preceded by a guard column (Varian). The column compartment was thermostated at $30^{\circ} \mathrm{C}$. The system was operated in isocratic mode with a mixture of $\mathrm{KH}_{2} \mathrm{PO}_{4} .50 \mathrm{mM}$ at $\mathrm{pH} 3.2$ (adjusted with phosphoric acid $1 \mathrm{M})(70 \%)$ and methanol (30\%). Analyses lasted $10 \mathrm{~min}$. Flow rate was $0.8 \mathrm{~mL} \mathrm{~min}^{-1}$ and sample injection volume was 5 or $10 \mu \mathrm{L}$. The detection of HTPA was done with the FLD, the excitation set at $250 \mathrm{~nm}$, and the emission at $440 \mathrm{~nm}$. The PDA was used at $245 \mathrm{~nm}$ for TPA detection. The system operation, data acquisition, calibration and quantitation were performed using ChemStation for LC 3D systems (Agilent).

Sensitivity of the method was evaluated with LOD and LOQ as for TPPO. The linearity of the response was established by building calibration curves with four concentration levels using individual solutions. Each calibration point was the average of two injections. 


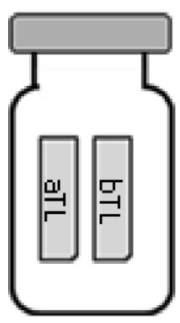

$\mathrm{A}$

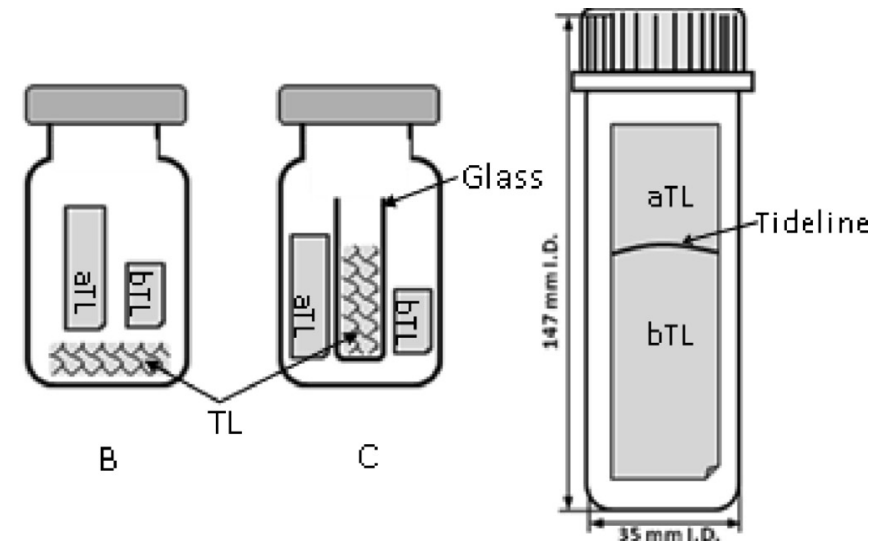

Fig. 2. Scheme of the hermetically closed vials used for hygrothermal aging: configurations A, B and C in $3 \mathrm{~mL}$ vials (left) and in $144 \mathrm{~mL}$ glass tube (right).

The calibration curves for TPA and HTPA were done over the concentration range $2.0 \times 10^{-6} \mathrm{M}$ to $2.0 \times 10^{-4} \mathrm{M}$ and $1.0 \times 10^{-9} \mathrm{M}$ to $5.0 \times 10^{-9} \mathrm{M}\left(5.0 \times 10^{-9} \mathrm{M}\right.$ to $5.0 \times 10^{-7} \mathrm{M}$ for the aged samples $)$, respectively.

In order to be able to compare the results, data is often reported in terms of moles of TPA or HTPA in a gram of paper.

\subsection{Molar mass determination by SEC/MALS}

\subsubsection{Hygrothermal aging}

Antioxidant impregnated papers were prepared according to the same procedure as reported in Section 2.4.1. The samples (with no tideline, i.e. equivalent' aTL) were aged in $3 \mathrm{~mL}$ crimp cap vials at $100^{\circ} \mathrm{C}$ for 5 days to act as control samples (Fig. 2 left (A)).

After the tideline formation, the aging was carried out according to ASTM D6819-02e02 standard where the whole paper sheets were aged at $100^{\circ} \mathrm{C}$ in $144 \mathrm{~mL}$ glass tubes (Fig. 2 right).

\subsubsection{Analysis}

The macromolecular characterization of cellulose was carried out by measuring the molar mass and molar mass distribution (MMD) using size-exclusion chromatography with multiangle light scattering and differential refractive index detection (SEC/MALS-DRI). The dissolution of the paper samples prior to the analysis was carried out in $\mathrm{N}, \mathrm{N}$-dimethylacetamide with $8 \%$ lithium chloride according to a procedure detailed in a previous publication (Dupont, 2003). An isocratic HPLC pump 515 (Waters), autosampler ACC-3000T (Dionex), Dawn EOS MALS detector (Wyatt Technologies), and 2414 (Waters) differential refractive index (DRI) detector were part of the chromatographic set-up. The separation was carried out on a set of three polystyrene divinyl benzene (PSDVB) columns Phenogel Linear(2) (5- $\mu \mathrm{m}$ particlediameter mixed bed pores columns, Phenomenex) preceded by a guard column Phenogel (5- $\mu \mathrm{m}$, Phenomenex). The columns compartment and the MALS detector were thermostated at $60^{\circ} \mathrm{C}$, the DRI was set to $55^{\circ} \mathrm{C}$. The mobile phase was $\mathrm{N}, \mathrm{N}$-dimethylacetamide with $0.5 \%$ lithium chloride (wt/vol). The system was operated at a flow rate of $0.4 \mathrm{~mL} \mathrm{~min}^{-1}$ with an injection volume of $100 \mu \mathrm{L}$. Each sample solution was run two times non-consecutively. The repeatability of the method as previously determined was $\mathrm{RSD} \%=2.5$ on $M_{w}$ for 3 separate cellulose samples analyzed two to three times non-consecutively.

\section{Results and discussion}

\subsection{Hydroperoxide analysis}

There are a number of methods available for quantitative determination of hydroperoxides (Dobarganes \& Velasco, 2002). Most of these methods are generic chemical methods which rely on redox reactions. The main limitation of these assays is the possible interference from minor compounds other than hydroperoxides, as well as their lack of specificity toward other oxidative species. Moreover, a total absence of oxygen and light has to be achieved during the reaction. For these reasons, the method that was chosen in this work for the analysis of hydroperoxides was one based on their reduction with triphenylphosphine (TPP) (Barnard \& Wong, 1976) (Scheme 3(a)). The reduction of hydroperoxides by trisubstituted phosphines has been shown to be highly specific (Denney, Goodyear, \& Goldstein, 1960; Stein \& Slawson, 1963). The triphenylphosphine oxide (TPPO) produced can be quantified using RP-HPLC (Nakamura \& Maeda, 1991). A method was presented in our previous work (Souguir et al., 2008).

\subsubsection{RP-HPLC method validation}

The two peaks of TPPO and TPP are completely resolved $\left(t_{R}=8.06\right.$ $( \pm 0.01) \mathrm{min}$ and $t_{R}=9.68( \pm 0.01) \mathrm{min}$, respectively $)$.

TPP contains a minute amount of TPPO which was subtracted from the TPPO peak area for precise quantitation as follows:

[ROOH] $\left(\mu \mathrm{mol} \mathrm{g}^{-1}\right) \approx([\mathrm{TPPO}]$ in paper $(\mu \mathrm{mol})$

- [TPPO] in blank (mmol))/paper mass $(\mathrm{g})$

The calibration curve, plotting peak area as a function of TPPO concentration indicated a linear regression coefficient $R^{2}$ of 0.9999 . The method shows high sensitivity for TPPO as well as for TPP. LOD was not investigated below $63 \mathrm{nM}$, the lowest concentration tested, for which $S^{\prime} / N$ was still about 390 . Both LOD and LOQ were thus defined as this threshold value.

\subsubsection{Quantitation of hydroperoxides in paper}

3.1.2.1. Effect of iron sulfate pretreatment. Trace metal levels are present in Whatman No. 1 paper. According to the manufacturer, $5 \mu \mathrm{gg}^{-1}$ of iron are present on average, while $3 \mu \mathrm{g} \mathrm{g}^{-1}$ had been previously measured in the paper batch used for this research (Jeong et al., 2012). The pretreatment with iron sulfate was carried out to achieve larger iron content in the paper $\left(\sim 100 \mu \mathrm{gg}^{-1}\right)$. This was expected to promote oxidation through the Fenton reaction (Scheme 1) (Walling, 1975), which would help evidencing the possible suppression effect of the antioxidants.

The samples were left to equilibrate for one week in controlled conditions $\left(23^{\circ} \mathrm{C}, 45 \pm 3 \% \mathrm{RH}\right)$ after the iron sulfate pretreatment since it was determined that a shorter period was not sufficient to bring hydroperoxides to substantially higher levels than in the control paper in any of the subdivided paper areas. Table 3 shows 
<smiles></smiles><smiles>[R]O[I+]c1ccccc1P(=O)(c1ccccc1)c1ccccc1</smiles>
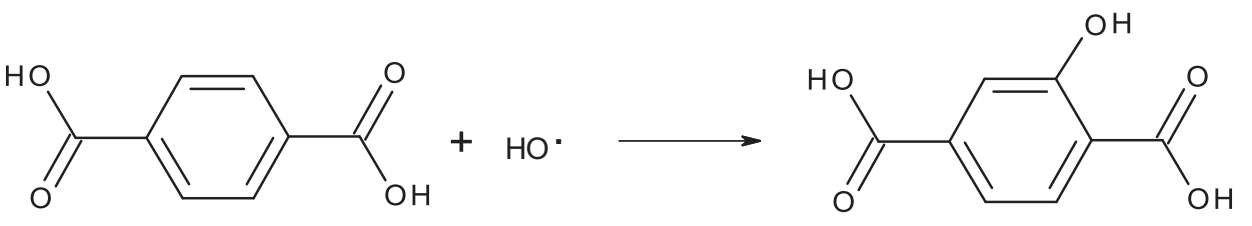

(b)

Scheme 3. Reduction of a hydroperoxide by triphenylphosphine (TPP) to form triphenylphosphine oxide (TPPO) and the corresponding alcohol (a), and hydroxylation of terephthalic acid (TPA) by hydroxyl radical to hydroxyl terephthalic acid (HTPA) (b).

the TPPO content of the control paper and of the iron sulfate pretreated paper (Fe-ref) in the different areas. In aTL and bTL the TPPO concentration was still not quantifiable for the control sample, and was extremely small in the papers pretreated with iron sulfate. In contrast, it was significantly higher in TL. The production of hydroperoxides during the tideline experiment clearly increased with the addition of iron in the paper.

It was observed that the papers and their tidelines exhibited different fluorescence in the visible when excited in the UV at $366 \mathrm{~nm}$. While the control tideline had a bright blue fluorescence, as already observed in previous research (Dupont, 1996a), the iron sulfate pretreated samples were darker and showed a dark blue line, which did not fluoresce (Fig. 3). Fluorescence may be suppressed by complexing of fluorophores with iron.

3.1.2.2. Antioxidant impregnation of iron sulfate pretreated papers. Table 3 shows that for the samples impregnated with $\mathrm{FeSO}_{4}$, T292 at the lowest concentration $(0.5 \%)$ reduced the amount of hydroperoxides in TL by about $40 \%$ compared to their amount in the reference sample (Fe-ref), but it did not at the highest concentration (2\%). It was also noticed that under visible light TL of the T292 impregnated paper was somewhat lighter than TL of the other paper samples (Fig. 4).

The samples treated with I168 at both concentrations $(0.5 \%$ and $2 \%$ ) showed highly reduced hydroperoxide content (>95\%) but no noticeable color attenuation of the tideline. There was no measurable TPPO either in the diffuse 'light brown' tideline area (LB-TL) of the paper impregnated with I168 (Fig. SI-3 left, in the Supporting information file).

The samples containing the mixture I168:T292 also showed a reduced amount of hydroperoxides (by $40 \%$ at the highest concentration and by $70 \%$ at the lowest concentration) and a significantly fainter tideline (Fig. 4). The samples containing $\mathrm{tBABr}$ and EMIMBr:T292 revealed a reduced amount of TPPO, while EMIMBr alone did not reduce the amount of TPPO in TL. With the halides treated papers, TPPO was found not only in the tideline but also in

Table 3

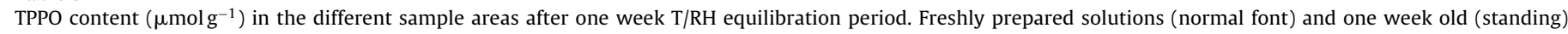
solutions (italics) $(\mathrm{SD}=$ standard deviation).

\begin{tabular}{|c|c|c|c|c|c|c|c|c|c|}
\hline & & $\mathrm{aTL}$ & $\mathrm{SD}$ & $\mathrm{TL}$ & SD & LB-TL & SD & bTL & SD \\
\hline No AO & $0.0 \%$ & ND & & 0.31 & 0.12 & - & & ND & \\
\hline (control: no $\mathrm{Fe} \mathrm{SO}_{4}$ ) & & - & & 0.73 & 0.02 & - & & - & \\
\hline No AO & $0.0 \%$ & 0.03 & 0.05 & 0.9 & 0.59 & 0.04 & 0.02 & 0.06 & 0.08 \\
\hline (Fe-ref) & & 0.09 & 0.01 & 2.18 & 0.01 & 0.08 & 0.01 & 0.17 & 0.01 \\
\hline \multirow[t]{4}{*}{ I168 } & $0.5 \%$ & ND & & 0.04 & 0.03 & ND & & ND & \\
\hline & & $N D$ & & 1.61 & 0.07 & $N D$ & & $N D$ & \\
\hline & $2.0 \%$ & ND & & ND & & ND & & ND & \\
\hline & & $N D$ & & $N D$ & & $N D$ & & $N D$ & \\
\hline \multirow[t]{4}{*}{ T292 } & $0.5 \%$ & ND & & 0.52 & 0.16 & - & & ND & \\
\hline & & 0.02 & 0.05 & 1.51 & 0.02 & - & & $N D$ & \\
\hline & $2.0 \%$ & ND & & 0.98 & 0.26 & 0.23 & 0.03 & 0.03 & 0.01 \\
\hline & & $N D$ & & 2.48 & 0.02 & 0.57 & 0.06 & $N D$ & \\
\hline \multirow[t]{4}{*}{ T292:I168 (1:1) } & $0.5 \%$ & ND & & 0.24 & 0.02 & - & & ND & \\
\hline & $2.0 \%$ & $N D$ & & 0.9 & 0.03 & - & & $N D$ & \\
\hline & & ND & & 0.51 & 0.12 & ND & & ND & \\
\hline & & $N D$ & & 1.41 & 0.01 & 0.18 & 0.03 & $N D$ & \\
\hline \multirow[t]{2}{*}{$\mathrm{tBABr}$} & $1.7 \%$ & 0.08 & 0.03 & 0.55 & 0.01 & 0.26 & 0.03 & 0.12 & 0.04 \\
\hline & & 0.08 & 0.05 & 0.44 & 0.05 & 0.31 & 0.01 & 0.17 & 0.07 \\
\hline \multirow[t]{2}{*}{ tBABr:T292 (0.85:1) } & $1.9 \%$ & ND & & 0.33 & 0.12 & 0.39 & 0.11 & ND & \\
\hline & & 0.02 & 0.05 & 1.05 & 0.01 & 0.79 & 0.03 & $N D$ & \\
\hline \multirow[t]{2}{*}{ EMIMBr } & $1.0 \%$ & 0.02 & 0.03 & 1.01 & 0.05 & - & & 0.04 & 0.02 \\
\hline & & 0.03 & 0.02 & 1.14 & 0.01 & - & & 0.01 & 0.02 \\
\hline \multirow[t]{2}{*}{ EMIMBr:T292 (0.5:1) } & $1.5 \%$ & 0.02 & 0.04 & 0.14 & 0.04 & 0.42 & 0.08 & ND & \\
\hline & & 0.06 & 0.01 & 0.38 & 0.03 & 0.74 & 0.01 & $N D$ & \\
\hline
\end{tabular}




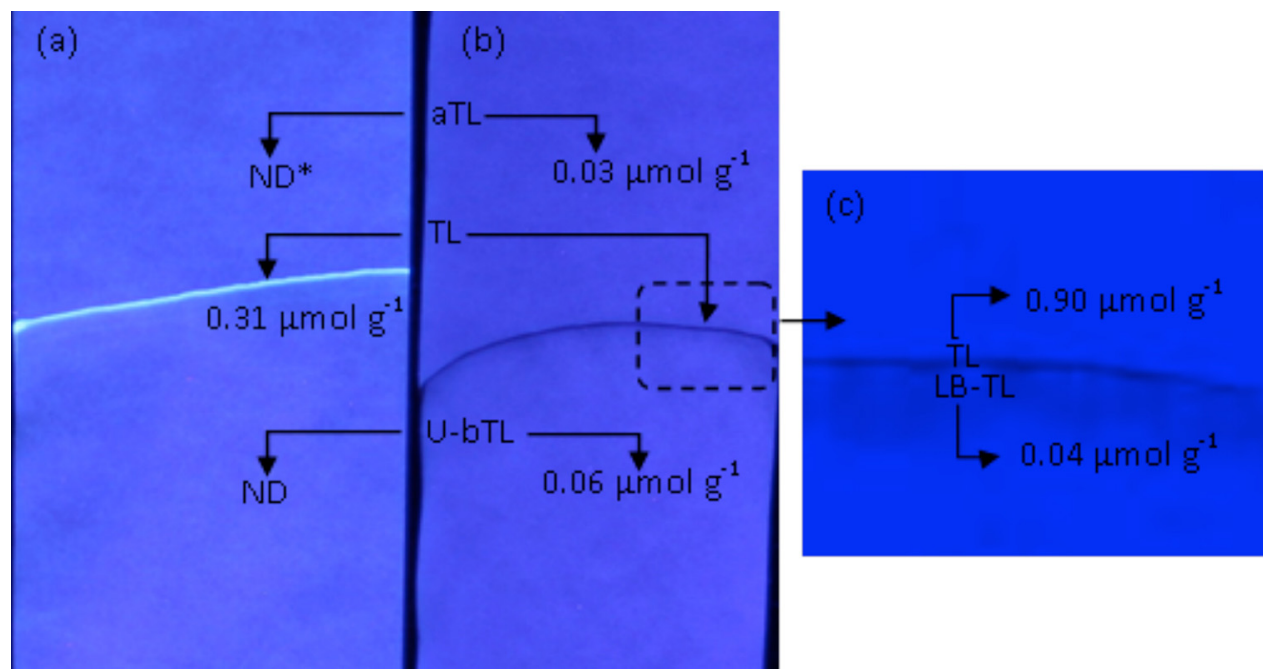

Fig. 3. (a) Control paper, (b) iron sulfate pretreated paper and (c) close-up view in TL area of (b) (image under UV at 366 nm). ND: no TPPO detected.

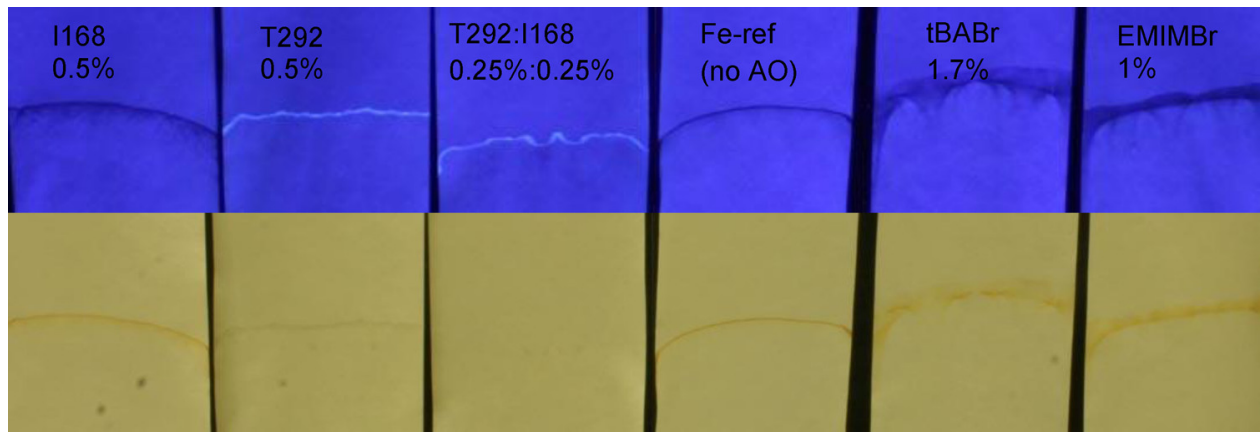

Fig. 4. Samples pretreated with iron sulfate and impregnated with antioxidants under visible (top) and UV $366 \mathrm{~nm}$ light (bottom). Percentages indicated are wt/wt.

the somewhat large 'light brown' tideline area above (LB-TL) (Fig. SI-3 right and Fig. SI-4, in the Supporting information file). The latter resulted from the spreading of the compounds at the wet/dry interface. The halides are about $70 \%$ water soluble and this may have affected the distribution of compounds in the tideline area, which makes it difficult to draw conclusions on the effectiveness of the two bromide antioxidants in this type of experiment.

The stability of the paper extracts was evaluated by measuring the evolution of the TPPO content in the liquid extracts one week after adding the TPP solution (standing time in solution) (Table 3, numbers in italics). It was found to increase considerably for TL samples without antioxidant (no AO), from the initial $0.31-0.73 \mu \mathrm{molg}^{-1}$ for the control sample, and from the initial $0.9-2.18 \mu \mathrm{mol} \mathrm{g}^{-1}$ for Fe-ref. This indicates that hydroperoxides were continuously produced in the solution, arising from the dissolved compounds present. No suppression effect after one week for the TL extract of the papers pretreated with $\mathrm{FeSO}_{4}$ and impregnated with T292 was observed: the hydroperoxide concentration increased quite similarly for the samples impregnated with $2 \% \mathrm{~T} 292$ (153\%) and $0.5 \%$ T292 (190\%) as for Fe-ref (142\%). However, the sample extracts of the papers pretreated with $\mathrm{FeSO}_{4}$ and impregnated with $\mathrm{I} 168$ 2\%, tBABr and EMIMBr showed no increase in the TPPO content in solution with time. It should be noted again that EMIMBr and $\mathrm{tBABr}$ being largely soluble in water, they can migrate during the tideline experiment as well as dissolve in the solvent mix used for sample preparation (water:methanol), which would explain their persistent effect in solution. On the contrary, the solubility of I168 in water is below $0.005 \mathrm{mg} \mathrm{L}^{-1}$. It is thus expected that it cannot substantially accumulate at the tideline, nor be significantly extracted in solution and so should be present in the sample extract in very small concentration. It is thus all the more noteworthy that I168 proved extremely efficient in suppressing hydroperoxide formation in the paper to the point that the aqueous extracts were stable during at least one week.

These results confirm our previous result that hydroperoxides are produced during tideline formation (Souguir et al., 2008) and show that once in solution the tideline extract continues to produce them with time.

\subsection{Hydroxyl radical analysis}

Direct and indirect methods can be used for the quantitative analysis of hydroxyl radicals. Electron Spin Resonance (ESR) spectroscopy is a direct method. It has been successfully used to study the formation of radicals in solutions of carbohydrates (Shkrob, Depew, \& Wan, 1993). However ESR is difficult to perform on purified cellulose due to high background noise level and low sensitivity (Linxiang et al., 2004). Furthermore, ESR does not allow a dynamic measurement during the tideline experiment or during the aging. Indirect methods are based on the use of chemical probes that react with $\mathrm{OH}^{\circ}$, the reaction products of which can be quantitated. These methods rely on the hydroxylation of aromatic compounds such as salicylate, phenylalanine, tryptophan, $N, N^{\prime}-(5-$ nitro,1,3-phenylene) bisglutaramide (NPG), 4-hydroxybenzoic acid (4-HBA) and terephthalic acid (TPA) (Fang, Mark, \& Sonntag, 1996; Freinbichler et al., 2008; Kolar, Strlič, \& Pihlar, 2001; Linxiang et al., 2004; Maskos, Rush, \& Koppenol, 1992; Matthews, 1980; Yan et al., 2005). Salicylate, phenylalanime, tryptophan and NPG produce multiple hydroxylated products, which is the main cause for poor detection limits. Due to their symmetrical structure, 4-HBA and 


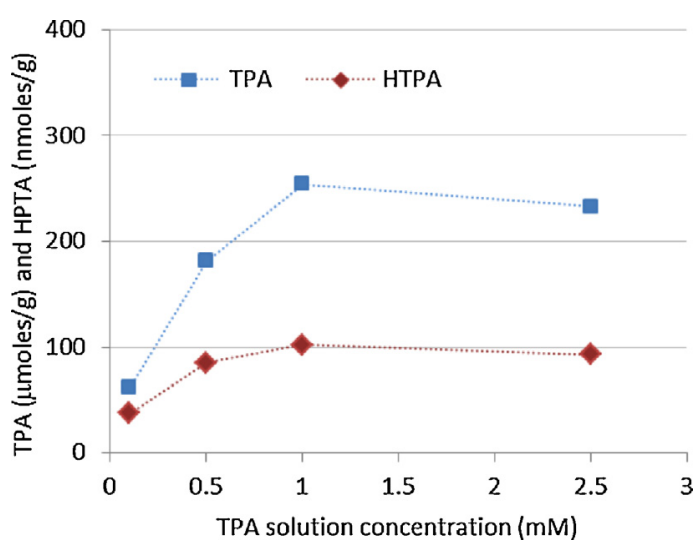

Fig. 5. HTPA ( $\left.\mathrm{nmolg}^{-1}\right)$ and TPA $\left(\mu \mathrm{molg}{ }^{-1}\right)$ content in TL as a function of TPA concentration in the impregnation solution.

TPA produce only one hydroxylated product, 3,4-hydroxybenzoic acid (3,4-HBA) and hydroxyl terephthalic acid (HTPA), respectively. HTPA has the advantage over 3,4-HBA that it fluoresces under UV (Scheme 3(b)). This allows for sensitive methods with very low LODs associated with the HPLC analysis using fluorescence rather than UV detection (Freinbichler et al., 2008).

\subsubsection{RP-HPLC method validation}

Two distinct peaks were obtained for HTPA and TPA, with $t_{R}=3.50( \pm 0.02) \mathrm{min}(\mathrm{FLD})$ and $t_{R}=5.97( \pm 0.02) \mathrm{min}(\mathrm{PDA})$, respectively. The calibration curve, plotting peak area as a function of HTPA concentration, indicated a linear regression coefficient $R^{2}$ of 0.9999 . The method shows high sensitivity with $\mathrm{LOD}=1.50 \mathrm{nM}$ and $102 \mathrm{nM}$ and $\mathrm{LOQ}=2.71 \mathrm{nM}$ and $468 \mathrm{nM}$ for HTPA and TPA, respectively.

\subsubsection{Quantitation of hydroxyl radicals in paper}

3.2.2.1. Effect of experimental parameters. If TPA was added to the TL sample right after the sequence of formation of the tideline and drying, no HTPA was detected. The very short lifetime and high reactivity of $\mathrm{OH}^{\bullet}$ would explain this absence. It is to circumvent this problem that the tideline was produced on paper impregnated with TPA, allowing the latter to react with $\mathrm{OH}^{\bullet}$ radicals as soon as they were produced.

HTPA was then found in much larger amounts in TL (Fig. 5 and Table 4 top). Using TPA impregnation solutions from 0.1 to $1 \mathrm{mM}$, both TPA and HTPA contents in TL and aTL gradually increased. For
TPA concentrations over $1 \mathrm{mM}$, no further increase in TPA and HTPA contents was found. This is consistent with the results reported previously for the equilibration periods (Section 2.4.2.2). The amounts of HTPA found in aTL were small and virtually no HTPA was present in any of the sub-divided bTL areas. This means that most of the HTPA present in the area bTL might have migrated with the water to TL. Therefore it seems that at least part of the HTPA in TL originates from the migration through the area bTL and not from de novo formation.

Table 4 (bottom) shows the HTPA and TPA contents as a function of water migration time in paper impregnated with TPA on which a tideline was produced. Confirming the results in Table 4 (top), the HTPA content in TL was found to be considerably higher than in the other areas in all cases. It also increased with migration time. As expected, in aTL the amount of TPA was more or less constant upon migration time as water only affects TL and bTL areas. The HTPA content in aTL however did increase, which was attributed to the time of exposure to air after the impregnation with TPA as explained above (Section 2.4.2.2). Plotting the HTPA content data for aTL in Table 4 as a function of equilibration time provided a linear plot with a slope of $0.025 \mathrm{nmol} \mathrm{g}^{-1} \mathrm{~h}^{-1}$ $\left(R^{2}=0.992\right)$, which confirms the natural rate of production of $\mathrm{OH}^{\bullet}$ in paper determined previously (Fig. SI-1(b) in the Supporting information file). Confirming the data in Table 4 (top), the HTPA content in bTL was much smaller compared with aTL, indicating that most HTPA and TPA have migrated to the tideline. HTPA in the upper area bTL (U-bTL) was nevertheless slightly higher than in the other subdivided bTL areas. This must be due to residual TPA in that area, which has undergone less water migration, and which can then react during the drying and equilibration period after formation of the tideline. Table 4 (bottom) also shows that the HTPA ratio TL/aTL as a function of migration time was rather constant. This again confirms that most HTPA found in TL actually originated from the migration of the HTPA present in the paper (in $\mathrm{bTL}$ ), which was probably produced during the $\mathrm{T} / \mathrm{RH}$ equilibration time after the TPA impregnation and before the tideline experiment. Since each sample underwent a different exposure time to air and humidity, this result tends to indicate that $\mathrm{OH}^{\circ}$ radicals are formed spontaneously in paper and originate primarily from exposure to ambient air. This is to our knowledge the first experimental evidence for the natural formation of $\mathrm{OH}^{\circ}$ in paper. Environmental research supports this as a plausible interpretation (Weschler \& Shields, 1997). Thus, there seems to be no evidence that hydroxyl radicals were produced more abundantly in TL than in aTL and bTL.

Table 4

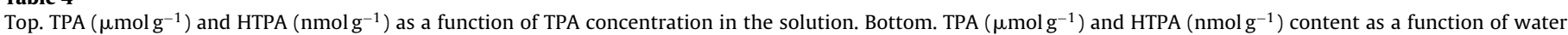
migration time (TPA impregnation solution $1 \mathrm{mM}$ ). Standard deviations are in parenthesis.

\begin{tabular}{|c|c|c|c|c|c|c|c|c|c|}
\hline & & & \multirow[t]{2}{*}{$\mathrm{aTL}$} & \multirow[t]{2}{*}{$\mathrm{TL}$} & \multicolumn{4}{|l|}{ bTL } & \multirow[t]{2}{*}{ TL/aTL } \\
\hline & & & & & U-bTL & M-bTL & L-bTL & B-bTL & \\
\hline \multirow{8}{*}{ TPA solution (mM) } & \multirow{2}{*}{0.1} & HTPA & $0.12(0.01)$ & $37.15(10.24)$ & ND & ND & ND & ND & \\
\hline & & TPA & $0.27(0.03)$ & $61.70(4.13)$ & ND & $0.01(0.01)$ & ND & $0.02(0.01)$ & \\
\hline & \multirow{2}{*}{0.5} & HTPA & $0.43(0.02)$ & $85.32(12.93)$ & $0.02(0.02)$ & $0.01(0.01)$ & ND & $0.04(0.03)$ & \\
\hline & & TPA & $1.09(0.03)$ & $181.62(13.96)$ & $0.01(0.01)$ & $0.01(0.01)$ & $0.02(0.02)$ & $0.01(0.01)$ & \\
\hline & \multirow[b]{2}{*}{1.0} & HTPA & $0.64(0.11)$ & $102.27(3.82)$ & $0.12(0.02)$ & $0.01(0.01)$ & ND & $0.01(0.01)$ & \\
\hline & & TPA & $2.22(0.04)$ & $253.73(7.62)$ & $2.37(0.04)$ & $0.02(0.01)$ & $0.01(0.01)$ & $0.04(0.03)$ & \\
\hline & \multirow{2}{*}{2.5} & HTPA & $0.52(0.13)$ & 93.30 (11.67) & $0.09(0.06)$ & $0.04(0.01)$ & $0.01(0.01)$ & $0.02(0.01)$ & \\
\hline & & TPA & $5.09(0.08)$ & $233.02(15.83)$ & $7.40(0.29)$ & $4.80(0.84)$ & $0.01(0.01)$ & $0.01(0.01)$ & \\
\hline \multirow{8}{*}{ Migration time (h) } & \multirow[b]{2}{*}{2} & HTPA & $0.29(0.04)$ & $45.42(11.16)$ & $0.06(0.04)$ & $0.06(0.01)$ & ND & $0.02(0.02)$ & 155.3 \\
\hline & & TPA & $2.26(0.04)$ & $181.67(26.31)$ & $2.39(0.09)$ & $1.16(0.28)$ & $0.25(0.26)$ & $0.82(0.02)$ & 80.5 \\
\hline & \multirow[b]{2}{*}{4} & HTPA & $0.35(0.02)$ & $52.45(14.13)$ & $0.06(0.01)$ & $0.02(0.03)$ & $0.02(0.02)$ & $0.1(0.01)$ & 151.4 \\
\hline & & TPA & $2.23(0.04)$ & $212.44(53.73)$ & $1.67(0.18)$ & $0.04(0.03)$ & $0.01(0.01)$ & $0.01(0.01)$ & 95.3 \\
\hline & \multirow{2}{*}{8} & HTPA & $0.47(0.02)$ & $68.64(11.84)$ & $0.07(0.02)$ & $0.01(0.01)$ & $0.01(0.01)$ & $0.01(0.01)$ & 146.9 \\
\hline & & TPA & $2.27(0.02)$ & $218.08(19.03)$ & $2.03(0.21)$ & $0.01(0.01)$ & $0.01(0.01)$ & $0.01(0.01)$ & 96.1 \\
\hline & \multirow{2}{*}{16} & HTPA & $0.64(0.11)$ & $102.27(3.82)$ & $0.12(0.02)$ & $0.01(0.01)$ & ND & $0.01(0.01)$ & 160 \\
\hline & & TPA & $2.22(0.04)$ & $253.73(7.62)$ & $2.37(0.04)$ & $0.02(0.01)$ & $0.01(0.01)$ & $0.04(0.03)$ & 114.1 \\
\hline
\end{tabular}


Table 5

HTPA content $\left(\mathrm{nmol} \mathrm{g}^{-1}\right)$ in samples aged 5 days at $100^{\circ} \mathrm{C}$ in the different configurations. Standard deviations are in parenthesis.

\begin{tabular}{lrll}
\hline Aging & \multicolumn{1}{c}{ aTL } & TL & U-bTL \\
\hline A & $79.8(6.7)$ & - & $64.7(5.6)$ \\
B & $109.0(4.5)$ & $29.6(4.4)$ & $81.3(4.5)$ \\
C & $83.6(7.3)$ & $40.9(6.0)$ & $74.1(6.9)$ \\
\hline
\end{tabular}

3.2.2.2. Effect of hygrothermal aging. The results so far indicate that if no significant hydroxyl radical formation occurs specifically during the tideline experiment, hydroxyl radicals do form naturally in paper with time at a specific rate. In order to further investigate this aspect of the oxidation artificial aging experiments were conducted.

Prior to performing the aging, it was verified that the production of HTPA would not originate from a reaction of TPA at high temperature. Indeed upon heating TPA $(0.166 \mu \mathrm{mol})$ at $100^{\circ} \mathrm{C}$ during 5 days in a $3 \mathrm{~mL}$-vial the amount of HTPA measured was negligible $(0.013 \mathrm{nmol})$.

TPA impregnated paper was then artificially aged at $100^{\circ} \mathrm{C}$ under different configurations, as described in Section 2.4.3. The HTPA content of aTL and bTL dramatically increased with aging in most aging configurations, and confirming previous results, it was higher in aTL than in bTL (Table 5). In contrast to previous results, however, the HTPA content in TL was the lowest of the three areas. Additionally, it was observed that when aged together with TL (configuration B), aTL and bTL had a higher HTPA content than when they were aged without TL (configuration $A$ ). These results are consistent with our previous study where it was shown that TL clearly affected co-aging samples (in same vial) from other areas in the paper, as monitored by a decrease in their molar mass, but that its own molar mass was affected the least (Jeong et al., 2012). In addition, in configuration $C$, where direct contact during aging between $\mathrm{TL}$ and the other co-aging samples was prevented by placing the TL sample in a separate small glass tube inside the aging vial, the HTPA content of aTL and bTL also increased. These results appear to evidence two phenomena. The first is that the impact of TL, in this case an increased $\mathrm{OH}^{\bullet}$ production in co-aging paper samples, must be related to a volatile fraction in the tideline. The second phenomenon is that non-volatile compounds present in the tideline have a counteracting effect on the in situ production of $\mathrm{OH}^{\circ}$, i.e. an antioxidant effect.

In order to investigate the origin of this production of HTPA, TPA $(0.166 \mu \mathrm{mol})$ was placed in a vial with paper samples (not previously impregnated with TPA) and underwent hygrothermal aging for 5 days in the same conditions as described previously. Two separate $3 \mathrm{~mL}$-vials were filled with TPA + aTL ( $82.8 \mathrm{mg})$, and TPA + TL (20.7 mg), respectively. Similarly as upon heating TPA alone, in both cases the amount of HTPA measured after aging was extremely small ( 0.012 and $0.019 \mathrm{nmol}$, respectively). This result has to be compared with the amount of HTPA found in aTL in aging configuration A, which was of $6.61 \mathrm{nmol}$ (Table 5: $79.8 \mathrm{nmol} \mathrm{g}^{-1} \times 0.0828 \mathrm{~g}$ paper). It therefore appears that $\mathrm{TL}$ did not release $\mathrm{OH}^{\circ}$ in the gas phase directly. More likely, TL releases volatile compounds that enhance the production of $\mathrm{OH}^{*}$ in the paper, as for example hydroperoxides.

3.2.2.3. Effect of antioxidants. Papers without tidelines containing different amounts of antioxidants (I168, T292, and their mixture) were hygrothermally aged for 5 days in configuration $A$ and their HTPA content determined (Table 6) (sample preparation as in Section 2.4.1). For the paper treated with T292, the higher the antioxidant content, the lower the amount of HTPA detected, but the HTPA content did not decrease further at concentrations of T292 above $0.5 \%$. No significant difference in HTPA was detected
Table 6

HTPA content $\left(\right.$ nmol g $\left.^{-1}\right)( \pm$ SD) in aTL aged 5 days (configuration A) depending on the antioxidant content $(\%, w t / w t)$ (samples $(10.3 \mathrm{mg}$ ) from eight different sheets were randomly selected and placed in each vial). Standard deviations are in parenthesis.

\begin{tabular}{llllll}
\hline Antioxidant & $0 \%$ & $0.05 \%$ & $0.1 \%$ & $0.5 \%$ & $1.0 \%$ \\
\hline Control & $62.1(1.5)$ & & & & \\
T292 & & $48.1(0.3)$ & $43.8(2.7)$ & $31.9(1.8)$ & $30.6(0.7)$ \\
I168 & & $57.7(1.2)$ & $56.7(0.2)$ & $54.5(4.8)$ & $57.6(2.9)$ \\
T292:I168(1:1) & $56.9(1.8)$ & $51.5(5.4)$ & $37.5(0.2)$ & $32.3(1.6)$ \\
T292:I168 (4:1) & $54.0(1.0)$ & $49.2(5.8)$ & $32.5(1.3)$ & $29.6(0.3)$ \\
\hline
\end{tabular}

for the papers with and without I168 whichever the antioxidant concentration, which is consistent with the operation mode of this antioxidant. In the mixtures I168:T292, the HTPA content was lower and was found to relate to the total antioxidant concentration, which was attributed to the relative proportion of T292 in the mixture.

Table 7 shows the HTPA content of aTL, TL and bTL in papers treated with antioxidants and aged 5 days in configuration $C$. Confirming the results upon aging of aTL in configuration A (Table 6), T292 was found to reduce the $\mathrm{OH}^{\bullet}$ content. Moreover, this was observed for all areas (aTL, TL, U-bTL). I168 somewhat reduced $\mathrm{OH}^{\bullet}$ content in aTL and bTL but more notably, did not affect the HTPA content in TL.

In Table 7 it can be seen that the HTPA content of aTL and bTL in the samples aged in configuration $C$ was somewhat smaller than that reported in Table 5. This difference was attributed to the fact that the two data sets were obtained with two different batches of paper. This assumption is supported by the measurement of the HTPA amount in aged aTL without antioxidant (Table 7), which was closer to that in Table 6 (same Whatman No. 1 batch) than to that in Table 5 (different Whatman No. 1 batch).

In conclusion, the results of hydroxyl radical and hydroperoxide analyses showed that I168 efficiently lowered the concentration of hydroperoxides and T292 that of hydroxyl radicals, which is consistent with the expected mode of action of these two antioxidants.

\subsection{Molar mass determinations}

The effect of the antioxidants on the degradation of cellulose during aging was also evaluated in terms of changes in molar mass. In a first set of experiments, molar mass determinations were done on papers impregnated with the antioxidants and without tidelines (aging configuration A, 5 days) (Fig. 2 and Table 8).

Upon aging, Whatman No. 1 control paper (no antioxidant) showed a decrease in $M_{w}$ of cellulose of $45 \%$ of its initial value, while the samples treated with antioxidants showed decreases in $M_{w}$ of 40\% (I168 0.5\%), 26\% (T292 0.5\%) and 22\% (T292:I168 0.5\%, in the two proportions tested). These results show that T292 was quite efficient at high temperature in inhibiting glycosidic bond breakage. Whether this beneficial effect was directly due to the

Table 7

HTPA content $\left(\mathrm{nmol} \mathrm{g}^{-1}\right)( \pm \mathrm{SD})$ in aTL, bTL and TL treated with $0.5 \%$ antioxidants (wt/wt) and aged 5 days (configuration C) depending on the antioxidant content (\%, $\mathrm{wt} / \mathrm{wt}$ ). Standard deviations are in parenthesis.

\begin{tabular}{llllll}
\hline & $\begin{array}{l}\text { Antioxidant } \\
\text { content } \\
\text { (\%,wt/wt) }\end{array}$ & & $\mathrm{aTL}$ & $\mathrm{TL}$ & $\mathrm{U}$-bTL \\
\cline { 2 - 5 } & $\mathrm{T} 292$ & $\mathrm{I} 168$ & & & \\
\hline Control & 0 & 0 & $63.9(1.8)$ & $33.9(2.5)$ & $55.5(1.1)$ \\
T292 & 0.50 & 0 & $32.1(1.7)$ & $21.6(2.8)$ & $30.9(0.8)$ \\
I168 & 0 & 0.50 & $45.4(0.2)$ & $34.4(1.5)$ & $35.8(1.0)$ \\
T292:I168(1:1) & 0.25 & 0.25 & $33.4(0.6)$ & $22.4(3.9)$ & $35.5(2.2)$ \\
T292:I168 (4:1) & 0.40 & 0.10 & $30.1(0.3)$ & $24.1(2.0)$ & $29.1(0.1)$ \\
\hline
\end{tabular}


Table 8

Number average $\left(M_{n}\right)$, weight average $\left(M_{w}\right)$ molar masses of cellulose $\left(\mathrm{kg} \mathrm{mol}^{-1}\right)$ and rate constant of glycosidic bond breakage $k^{\prime} t_{120 \mathrm{~h}, 100^{\circ} \mathrm{C}}$ (measured as the slope in

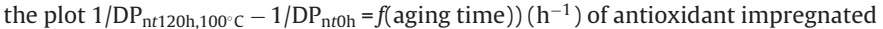
paper (aTL area) (aging configuration A).

\begin{tabular}{llllll}
\hline & $\begin{array}{l}\text { Antioxidant in } \\
\text { paper }(\%, \mathrm{wt} / \mathrm{wt})\end{array}$ & $M_{n}$ & $M_{w}$ & $k^{\prime} t_{120 \mathrm{~h}, 100^{\circ} \mathrm{C}}$ \\
\cline { 2 - 5 } & $\mathrm{T} 292$ & $\mathrm{I} 168$ & & & \\
\hline Unaged control & 0 & 0 & 312 & 492 & \\
5-days aged control & 0 & 0 & 169 & 270 & $2.72 \times 10^{-4}$ \\
T292 & 0.50 & 0 & 202 & 365 & $1.15 \times 10^{-4}$ \\
I168 & 0 & 0.50 & 167 & 296 & $2.17 \times 10^{-4}$ \\
T292:I168 (1:1) & 0.25 & 0.25 & 228 & 380 & $9.72 \times 10^{-5}$ \\
T292:I168 (4:1) & 0.40 & 0.40 & 233 & 384 & $9.18 \times 10^{-5}$ \\
\hline
\end{tabular}

suppression of hydroxyl and other free radicals is not entirely clear. A few publications report on cellulose glycosidic bonds scissions due to oxidation reactions (Fengel \& Wegener, 1984; Lewin, 1997; Mosca Conte et al., 2012). In the case of T292, the effect of the alkaline properties of the amine moiety in decreasing the rate of glycosidic bonds scissions has to be examined, as alkaline moieties are well-known to counteract acid catalyzed hydrolysis, which is the main degradation mechanism during hygrothermal exposure. This is the rationale for widely used deacidification methods in paper conservation, which are known to enhance paper longevity. The 'alkaline reserve' in the paper treated with T292 is however negligible as theoretically calculated $\left(7.5 \mathrm{mEq} \mathrm{OH} \mathrm{OH}^{-} / 100 \mathrm{~g}\right.$ at most for the samples treated with $2 \% \mathrm{~T} 292$ ), and is null as measured using the TAPPI standard method T 553 om-00. Moreover, the pH of the papers treated with T292 varied widely, from 6.3 to 9 , for concentrations of $0.5 \%$ and $2 \%$, respectively. Furthermore, it has been shown that for cotton papers, a variation of $\mathrm{pH}$ departing 5 to $15 \%$ above neutrality had little influence in lowering the decrease in DP upon hygrothermal aging (Malešič, Kolar, \& Strlič, 2002). It is thus unlikely that alkalinity alone could explain the large reduction in the degradation rates observed. For purposes of permanence and efficient molar mass retention upon natural aging, alkaline reserve usually recommended in paper is $40 \mathrm{mEq} \mathrm{OH}^{-} / 100 \mathrm{~g}$ (ISO 9706:1994). It is therefore more likely that the reduction in $\mathrm{OH}^{\bullet}$ and other free radicals plays a major role in lowering the rate of glycosidic bonds scissions.

Compared with the control paper, the rate of glycosidic bond breakage (Ekamstam, 1936) upon 5 days aging $(120 \mathrm{~h})$, called

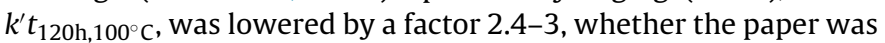
impregnated with T292 or with T292:I168, which indicates that the molar mass retention is primarily due to 7292 . This result favors the interpretation that protection against glycosidic bond scissions of cellulose is largely due to the suppression by the antioxidants of oxidation species. The issue of the efficiency of the anti-oxidants versus their concentration in the paper, which could not be fully investigated here, certainly would deserve a more in-depth study.

In a second set of experiments papers were impregnated with antioxidants after which the tideline experiment was done and the whole sheets were hygrothermally aged in large tubes $(144 \mathrm{~mL})$ as shown in Fig. 2. Table 9 shows $M_{w}$ in the different areas. Upon impregnation with T292, $M_{w}$ for aTL was quite similar at the two concentrations tested, $0.5 \%$ and $2 \%$, (about $11 \%$ and $15 \%$ less decrease in $M_{w}$ than the control sample, respectively). T292 at $0.5 \%$ was sufficient to significantly slow down cellulose degradation, which is consistent with the results for the hydroxyl radical analysis and in agreement with $M_{w}$ of aTL when aged in $3 \mathrm{~mL}$ vial in configuration A (Table 8). In the case of TL and bTL, the evolution of $M_{w}$ was different than for aTL, with TL in particular being the most degraded. For bTL, T292 lowered the rate of glycosidic bonds scission, and more efficiently so (19\%) at the highest concentration. Conversely, chain scissions upon aging in TL for the T292
Table 9

Weight average molar masses $\left(M_{w}\right)$ of Whatman No. 1 paper impregnated with antioxidants in the different areas after aging in $144 \mathrm{~mL}$ closed tube for 5 days.

\begin{tabular}{|c|c|c|c|c|c|}
\hline & \multicolumn{2}{|c|}{$\begin{array}{l}\text { Antioxidant in } \\
\text { paper }(\%, w t / w t)\end{array}$} & \multirow[t]{2}{*}{$\mathrm{aTL}$} & \multirow[t]{2}{*}{$\mathrm{TL}$} & \multirow[t]{2}{*}{ bTL } \\
\hline & T292 & I168 & & & \\
\hline Control aged & 0 & 0 & 309 & 317 & 262 \\
\hline \multirow{2}{*}{ T292 } & 0.50 & 0 & 348 & 254 & 277 \\
\hline & 2.00 & 0 & 361 & 230 & 324 \\
\hline \multirow[b]{2}{*}{ I168 } & 0 & 0.50 & 302 & 298 & 234 \\
\hline & 0 & 2.00 & 96 & 160 & 58 \\
\hline \multirow{2}{*}{$\begin{array}{l}\text { T292:I168 } \\
(1: 1)\end{array}$} & 0.25 & 0.25 & 346 & 225 & 270 \\
\hline & 1.00 & 1.00 & 364 & 190 & 322 \\
\hline
\end{tabular}

impregnated samples were more abundant than in TL of the control sample. This was observed for TL samples of all the antioxidant impregnated papers, and especially for I168. It was also more pronounced at the higher antioxidant concentrations. For the paper impregnated with $2 \%$ I168, the results show that the degradation upon aging was larger than for the control samples in all the areas. This unexpected result shows the complexity of the reactions taking place during aging. Although I168 is considered to be less prone to hydrolysis than other types of phophite antioxidants (Tocháček \& Sedlár, 1993), the hypothesis of acid production due to hydrolysis of I168 upon thermal exposure can be proposed, which would cause enhanced acid-catalyzed hydrolysis of glycosidic bonds.

\section{Conclusion}

This study focused on cellulose oxidation reactions at the wet/dry interface in paper, specifically the formation of hydroperoxides and hydroxyl radicals, and the effects of antioxidants. Micromolar range levels of hydroperoxides per gram of paper were found in freshly formed tidelines. This concentration increased upon natural aging and upon pretreatment of the paper with iron sulfate. A phosphite antioxidant, Irgafos 168, was found to considerably reduce the occurrence of hydroperoxides. Conversely, there seems to be no evidence that hydroxyl radicals were produced as a consequence of the tideline experiment. It was found that most hydroxyl radicals measured in the tideline originated from reactive species present in the paper, which reacted with the terephthalic acid (TPA) and migrated to the tideline area with the water raise. It was shown that hydroxyl radicals form spontaneously in paper. On the other hand, the hydroxy terephthalic acid (HTPA) content considerably increased upon hygrothermal aging in a closed system. The presence of the tideline in the aging vial led to an increase in the hydroxyl radical content in co-aging paper samples (aTL, bTL), while hydroxyl radical content in the tideline itself appeared to be the lowest. Future research is still needed to fully explain this but these observations illustrate the complexity of the chemical composition of the tideline. The presence of a volatile fraction, which promotes oxidation of neighboring paper (co-aging samples), and a non-volatile fraction, which counteracts in situ oxidation, seems the most likely explanation. Hydroperoxides, which are present in high concentration in tidelines are likely to play a role during aging. Oxidation products such as the volatile low molar mass formic and acetic acids, which have been found in large amounts tidelines (Souguir et al., 2008), would catalyze hydrolysis reactions during aging, leading to decreased molar mass of adjacent paper samples, as proposed by Jeong et al. (2012). Formic acid in particular would have a crucial part, not only because this acid is the most abundantly present in the tideline, but also because it has been identified recently as very aggressive in vapour phase for paper, being responsible for significant molar mass decrease of cellulose even at room temperature (Tétreault, Dupont, Bégin, \& Paris, 2013). Noteworthy is the fact that in tidelines it has been shown to be present 
also partly in its (non-volatile) carboxylate form, formate (Jeong et al., 2012; Souguir et al., 2008), which is known to be a hydroxyl radical scavenger (Buettner \& Mason, 1990). Non-volatile phenolic compounds produced from acid-catalyzed dehydration and condensation reactions of sugars (Popoff \& Theander, 1976; Rosenau et al., 2011) could also play a role in the observed antioxidant behavior.

The hindered amine stabilizer Tinuvin 292 reduced the hydroxyl radical concentration. Although acid catalyzed hydrolysis of glycosidic bonds is the main mechanism in cellulose during hygrothermal aging, it is clear that oxidation reactions play a significant role in the specific case of papers containing tidelines. Indeed the incorporation of Tinuvin 292 in the paper succeeded in lowering the degradation rate of cellulose. This finding is of potential interest in the broader scope of paper conservation and paper durability studies. Indeed, although research on the oxidative degradation of cellulose during aging is scarce, some results support the fact that oxidation reactions play a role, even in paper without tidelines (Arney \& Jacobs, 1979, 1980; Arney \& Novak, 1982; Kleinert \& Marraccini, 1963, 1966a, 1966b; Marraccini \& Kleinert, 1962; Tétreault et al., 2013). Most studies on oxidative reactions in cellulose have used alkaline conditions and further investigation of the influence of pH is therefore paramount (Minor \& Sanyer, 1971; Williams, Fowler, Lyon, \& Merrill, 1978).

\section{Acknowledgements}

The CNRS and the Andrew W. Mellon Foundation are acknowledged for financial support. Warm thanks are also due to Christopher Maines, Suzanne Lomax and Zied Souguir for helpful discussions and to Sabrina Paris for the technical help.

\section{Appendix A. Supplementary data}

Supplementary data associated with this article can be found, in the online version, at http://dx.doi.org/10.1016/j.carbpol. 2013.09.080.

\section{References}

Arney, J. S., \& Jacobs, A. J. (1979). Accelerated aging of paper. The relative importance of atmospheric oxidation. TAPPI, The Journal of Technical Association of the Pulp and Paper Industry, 62(7), 89-91.

Arney, J. S., \& Jacobs, A. J. (1980). Newsprint deterioration. The influence of temperature on the relative contribution of oxygen-independent and oxygen-dependent processes in the total rate. TAPPI, The Journal of Technical Association of the Pulp and Paper Industry, 63(1), 75-77.

Arney, J. S., \& Novak, C. L. (1982). Accelerated aging of paper. The influence of acidity on the relative contribution of oxygen-independent and oxygen-dependent processes. TAPPI, The Journal of Technical Association of the Pulp and Paper Industry, 65(3), 113-115.

Barnard, D., \& Wong, K. C. (1976). The determination of small amounts of organic hydroperoxides with triphenylphosphine. Analytica Chimica Acta, 84, 355-361.

Bogaty, H., Campbell, K. S., \& Appel, W. D. (1952). Some observations on the evaporation of water from cellulose. Textile Research Journal, 22, 25-81.

Bone, W. H., \& Turner, H. A. (1950). Some effects of the evaporation of water from cotton cellulose. Journal of the Society of Dyers and Colourists, 66, 315-327.

Buettner, G. R., \& Mason, R. P. (1990). Spin-trapping methods for detecting superoxide and hydroxyl free radicals in vitro and in vivo. Methods in Enzymology, 186, 127-133.

Calvini, P., \& Silveira, M. (2008). FTIR analysis of naturally aged $\mathrm{FeCl}_{3}$ and $\mathrm{CuCl}_{2}$ doped cellulose papers. E-Preservation Science, 5, 1-8.

Denney, D. B., Goodyear, W. F., \& Goldstein, B. (1960). Concerning the mechanism of the reduction of hydroperoxides by trisubstituted phosphines and trisubstituted phosphites. Journal of the American Chemical Society, 82(6), 1393-1395.

Dobarganes, M. C., \& Velasco, J. (2002). Analysis of lipid hydroperoxides. European Journal Lipid Science and Technology, 104, 420-428.

Dupont, A.-L. (1996a). Degradation of cellulose at wet/dry interface: I. The effect of some conservation treatments on brown lines. Restaurator, International Journal for the Preservation of Library and Archival Material, 17(1), 1-21.

Dupont, A.-L. (1996b). Degradation of cellulose at wet/dry interface: II. An approach to the identification of the oxidation compounds. Restaurator, International Journal for the Preservation of Library and Archival Material, 17(3), 145-164.
Dupont, A.-L. (2003). Cellulose in lithium chloride/N,N-dimethylacetamide, optimisation of a dissolution method using paper substrates and stability of the solutions. Polymer, 44, 4117-4126.

Ekamstam, A. (1936). The behaviour of cellulose in mineral acid solutions: Kinetic study of the decomposition of cellulose in acid solution. Berichte der Deutschen Chemischen Gesellschaft, 69A, 553-559.

Eusman, E. (1995). Tideline formation in paper objects: Cellulose degradation at the wet-dry boundary. Conservation research, studies in the history of art, monograph series II. National Gallery of Art, Washington, 51, 11-27.

Fang, X., Mark, G., \& Sonntag, C. (1996). OH radical formation by ultrasound in aqueous solutions. Part I: The chemistry underlying the terephthalate dosimeter. Ultrasonics Sonochemistry, 3, 57-63.

Fengel, D., \& Wegener, G. (1984). Wood Chemistry, Ultrastructure, Reactions. New York, Berlin: Walter de Gruyter (Reactions in Acidic Medium. Chapter 10)

Freinbichler, W., Bianchi, L., Colivicchi, M. A., Ballini, C., Tipton, K. F., Linert, W., et al. (2008). The detection of hydroxyl radicals in vivo. Journal of Inorganic Biochemistry, 102, 1329-1333.

Gugumus, F. (1994). Mechanisms of thermooxidative stabilization with HAS. Polymer Degradation and Stability, 44, 299-322.

Hofenk de Graaff, J. H. (1994). Research into the cause of browning of paper mounted in mats. Contributions of the Central Research Laboratory to the Field of Conservation and Restoration, 21-42.

ISO 9706: 1994. (1994). Information and documentation - Paper for documents Requirements for permanence. Geneva, Switzerland: International Organization for Standardization.

Jeong, M.-J., Dupont, A.-L., \& De la Rie, E. R. (2012). Degradation of cellulose at the wet-dry interface. I. Study of the depolymerization. Cellulose, 19, 1135-1147.

Kleinert, T. N., \& Marraccini, L. M. (1963). Aging and colour reversion of bleached pulps. Part 2. Influence of air and moisture. Svensk Papperstidning, 66(6), 189-195.

Kleinert, T. N., \& Marraccini, L. M. (1966a). Aging and colour reversion of bleached pulps. Part 3. Pulp extractives from air aging at high humidity. Svensk Papperstidning, 69(5), 159-160.

Kleinert, T. N., \& Marraccini, L. M. (1966b). Aging and colour reversion of bleached pulps. Part 4. The role of the aldehyde end group. Svensk Papperstidning, 69(3), 69-71.

Kočar, D., Strlič, M., Kolar, J., Rychlý, J., Matisová-Rychlá, L., \& Pihlar, B. (2005). Chemiluminescence from paper III: The effect of superoxide anion and water. Polymer Degradation and Stability, 88, 407-414.

Kolar, J. (1997). Mechanism of autoxidative degradation of cellulose. Restaurator, International Journal for the Preservation of Library and Archival Material, 18 163-176.

Kolar, J., Strlič, M., Novak, G., \& Pihlar, B. (1998). Aging and stabilization of alkaline paper. Journal of Pulp and Paper Science, 24(3), 89-94.

Kolar, J., Strlič, M., \& Pihlar, B. (2001). New colourimetric method for determination of hydroxyl radicals during ageing of cellulose. Analytica Chimica Acta, 431, 313-319.

Kolar, J., Možir, A., Strlič, M., de Bruin, G., Pihlar, B., \& Steemers, T. (2007). Stabilisation of iron gall ink: Aqueous treatment with magnesium phytate. E-Preservation Science, 4, 19-24.

Lai, Y.-Z. (2001). Chemical degradation. In N. Hon, \& S. N. Shiraishi (Eds.), Wood and cellulosic chemistry (2nd ed., pp. 443-512). New-York, Basel: Marcel Dekker Inc (Chapter 10).

Lewin, M. (1997). Oxidation and aging of cellulose. Macromolecular Symposia, 118, $715-724$.

Linxiang, L., Abe, Y., Nagasawa, Y., Kudo, R., Usui, N., Imai, K., et al. (2004). An HPLC assay of hydroxyl radicals by the hydroxylation reaction of terephthalic acid Biomedical Chromatography, 18(7), 470-474.

Luo, W., Abbas, M. E., Zhua, L., Deng, K., \& Tang, H. (2008). Rapid quantitative determination of hydrogen peroxide by oxidation decolorization of methyl orange using a Fenton reaction system. Analytica Chimica Acta, 629, 1-5.

Madaras, G. W., \& Turner, H. A. (1953). Further observations on the effects of evaporating water from cotton cellulose. Journal of the Society of Dyers and Colourists, 69, 371-377.

Malešič, J., Kolar, J., \& Strlič, M. (2002). Effect of pH and carbonyls on the degradation of alkaline paper. Restaurator, International Journal for the Preservation of Library and Archival Material, 23, 145-153.

Malešič, J., Strlič, M., Kolar, J., \& Polanc, S. (2005). The influence of halide and pseudohalide antioxidants in Fenton-like reaction systems containing copper(II) ions. Journal of Molecular Catalysis A: Chemical, 241, 126-132.

Marraccini, L. M., \& Kleinert, T. N. (1962). Aging and colour reversion of bleached pulps. Part 1. Peroxide formation during aging. Svensk Papperstidning, 65(4), 126-131.

Maskos, Z., Rush, J. D., \& Koppenol, W. H. (1992). The hydroxylation of phenylalanine and tyrosine: A comparison with salicylate and tryptophan. Archives of Biochemistry and Biophysics, 296(2), 521-529.

Matthews, R. W. (1980). The radiation chemistry of the terephthalate dosimeter. Radiation Research, 83(1), 27-41.

Minor, J. L., \& Sanyer, N. (1971). Oxygen/alkali oxidation of cellulose and model alcohols and the inhibition by iodide. Journal of Polymer Science: Part C, 36, 73-84.

Mosca Conte, A., Pulci, O., Knapik, A., Bagniuk, J., Del Sole, R., Lojewska, J., et al. (2012). Role of cellulose oxidation in the yellowing of ancient paper. Physical Review Letters, 108, 158301-1-158301-5.

Nakamura, T., \& Maeda, H. (1991). A simple assay for lipid hydroperoxides based on triphenylphosphine oxidation and HPLC. Lipids, 26(9), 765-768. 
Neevel, J. G. (1995). Phytate: A potential conservation agent for the treatment of ink corrosion caused by iron gall inks. Restaurator, International Journal for the Preservation of Library and Archival Material, 16, 143-160.

Pospíšil, J., \& Nespurek, S. (1995). Chain-breaking stabilizers in polymers: The current status. Polymer Degradation and Stability, 49, 99-110.

Popoff, T., \& Theander, O. (1976). Formation of aromatic compounds from carbohydrates, Part III. Reaction of D-Glucose and D-fructose in slightly acidic, aqueous solution. Acta Chemica Scandinavica, B30, 397-402.

Prousek, J. (2007). Fenton chemistry in biology and medicine. IUPAC, Pure and Applied Chemistry, 79(12), 2325-2338.

Rosenau, T., Potthast, A., Krainz, K., Yoneda, Y., Dietz, T., Shields, Z. P.-I., et al. (2011). Chromophores in cellulosics. VI. First isolation and identification of residual chromophores from aged cotton linters. Cellulose, 18, 1623-1633.

Rouchon, V., Duranton, M., Burgaud, C., Pellizzi, E., \& Lavédrine, B. (2011). Roomtemperature study of iron gall ink impregnated paper degradation under various oxygen and humidity conditions: Time-dependent monitoring by viscosity and $\mathrm{X}$-ray absorption near-edge spectrometry measurements. Analytical Chemistry, 83, 2589-2597.

Schmidt, J. A., Rye, C. S., \& Gurna, N. (1995). Lignin inhibits autoxidative degradation of cellulose. Polymer Degradation and Stability, 49, 291-297.

Scott, G. (1993). Atmospheric oxidation and antioxidants. Amsterdam: Elsevier.

Shkrob, I. A., Depew, M. C., \& Wan, J. K. S. (1993). Time-resolved electron spin resonance study of radical species derived from naturally occurring carbohydrates. Chemical Physics Letters, 202, 133-140.

Snyder, L. R., Kirkland, J. J., \& Glajch, J. L. (1997). Practical HPLC method development (2nd ed.). New York: John Wiley \& Sons.

Souguir, Z., Dupont, A. -L., \& De la Rie, E. R.(2008). Formation of brown lines in paper: Characterization of cellulose degradation at the wet-dry interface. Biomacromolecules, 9, 2546-2552.
Stein, R. A., \& Slawson, V. (1963). Spectrophotometric hydroperoxide determination by the use of triphenylphosphine. Analytical Chemistry, 35(8), 1008-1010.

Stephens, C. H., Barrett, T., Whitmore, P. M., Wade, J. A., Mazurek, J., \& Schilling, M. (2008). Composition and condition of naturally aged papers. Journal of the American Institute for Conservation, 47(3), 201-215.

Strlič, M., Kolar, J., \& Pihlar, B. (2001). Some preventive cellulose antioxidants studied by an aromatic hydroxylation assay. Polymer Degradation and Stability, 73, $535-539$.

T 553 om-00. (2000). Alkalinity of paper as calcium carbonate (alkaline reserve of paper). Norcross, GA, USA: Technical Association of the Pulp and Paper Industry.

Tétreault, J., Dupont, A.-L., Bégin, P., \& Paris, S. (2013). The impact of carbonyl and hydrogen peroxide vapours on cellulose degradation under ambient hygrothermal conditions. Polymer Degradation and Stability, 98, 1827-1837.

Tocháček, J., \& Sedlář, J. (1993). Effect of hydrolysability and structural features of phosphites on processing stability of isotactic polypropylene. Polymer Degradation and Stability, 41, 177-184.

Walling, C. (1975). Fenton's reagent revisited. Accounts of Chemical Research, 8(4), $125-131$.

Weschler, C. J., \& Shields, H. C. (1997). Potential reactions among indoor pollutants. Atmospheric Environment, 31, 3487-3495.

Yan, E. B., Unthank, J. K., Castillo-Melendez, M., Miller, S. L., Langford, S. J., \& Walker, D. W. (2005). Novel method for in vivo hydroxyl radical measurement by microdialysis in fetal sheep brain in utero. Journal of Applied Physiology, 98(6), 2304-2310.

Williams, J. C., Fowler, C. S., Lyon, M. S., \& Merrill, T. L. (1978). Metallic catalysts in the oxidative degradation of paper. In J. Williams (Ed.), Preservation of paper and textiles of historic and artistic value. Advances in chemistry (vol. 164) (pp. 37-61). Washington, DC: American Chemical Society. 